\title{
CRESCIMENTO INICIAL, FERTILIDADE DO SOLO E NUTRIÇÃO DE UM POVOAMENTO DE Eucalyptus grandis FERTILIZADO COM BIOSSÓLIDO
}

\author{
LuCiano Mendes Souza Vaz \\ BIÓLOGO
}

Orientador: Prof. Dr. JoSÉ LeONARdo DE MORAES GonÇALVES

Dissertação apresentada à Escola Superior de Agricultura "Luiz de Queiroz", Universidade de São Paulo, para obtenção do título de Mestre em Ciências, Área de Concentração: Ciências Florestais.

PIRACICABA

Estado de São Paulo - Brasil

Setembro - 2000 
Dados Internacionais de Catalogaçāo na Publicação (CIP) DIVISÃO DE BIBLIOTECA E DOCUMENTAÇÃO - Campus "Luiz de Oueiroz"/USP

\author{
Vaz, Luciano Mendes Souza \\ Crescimento inicial, fertilidade do solo e nutrição de um povoamento de Eucalyptus \\ grandis fertilizado com biossólido / Luciano Mendes Souza Vaz. - Piracicaba : 2000. \\ $41 \mathrm{p}$. \\ Dissertaçāo (mestrado) - - Escola Superior de Agricultura Luiz de Queiroz, 2000. \\ Bibliografia. \\ 1. Crescimento vegetal 2. Eucalipto 3. Fertilidade do solo 4. Lodo de esgoto 5. \\ Nutrição mineral 6. Povoamento florestal I. Título
}

CDD 634.9734 
A Deus, pela constante presença OFEREÇO

Ao meu querido Gabriel

DEDICO 


\section{AGRADECIMENTOS}

Expresso a minha sincera gratidão às instituições e pessoas que, direta ou indiretamente, colaboraram para a realização deste trabalho, em especial as relacionadas a seguir:

Ao Professor Dr. José Leonardo de Moraes Gonçalves, pela orientação, conselhos e amizade.

À Escola Superior de Agricultura "Luiz de Queiroz", pela oportunidade de ingressar no curso de pós graduação em Ciências Florestais.

À SABESP pelo apoio financeiro durante todo o trabalho.

À CAPES, pela bolsa de estudos concedida. À FAPESP pelo auxílio a pesquisa concedido.

A equipe do Laboratório de Ecologia Aplicada (LEA), em especial a Química Alba Valéria Masseto.

Aos meus pais, Roque Raimundo Souza Vaz e Maria Dalva Souza Vaz, a quem devo profundo carinho e admiração.

A Andréa da Silva Alves e Sueli da Silva Alves pelo carinho, apoio e incentivo durante este trabalho.

Aos queridos amigos de república: Eng ${ }^{\circ}$ Roberto Hiroyuki Konno, Eng ${ }^{\circ}$ Luís Pedro de Melo Plese e Eng ${ }^{\circ}$ Cristiano Alberto de Andrade, pelos momentos agradáveis, a convivência, e a paciência dispensados.

Ao Eng ${ }^{\circ}$ Florestal Luiz Carlos de Faria pela fundamental ajuda no campo e amizade.

Ao Eng ${ }^{\circ}$ Florestal Marcelino Carneiro Guedes e ao $\mathrm{Eng}^{\circ}$ Florestal Vanderlei Benedetti

A querida bióloga Claúdia Regina da Silva pela paciência e amizade.

Aos professores Fábio Pogianni, Maria Emilia Mattiazzo-Prezzoto, Luiz Carlos Estraviz pelas críticas, correções e sugestões apresentadas.

Aos amigos do curso de pós-graduação que ajudaram a diminuir a pressão das responsabilidades e pelos momentos felizes. 


\section{SUMÁRIO}

Página

LISTA DE FIGURAS....................................................................... v

LISTA DE TABELAS .............................................................................. vi

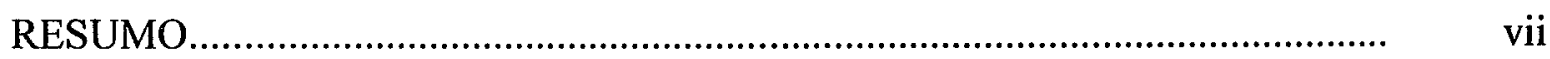

ABSTRACT ......................................................................................... ix

1 INTRODUÇÃ

2 REVISÃO DE LITERATURA........................................................... 3

2.1 Definição de lodo de esgoto e biossólido..................................................... 3

2.2 Potencial de uso do biossólido em plantações florestais................................. 4

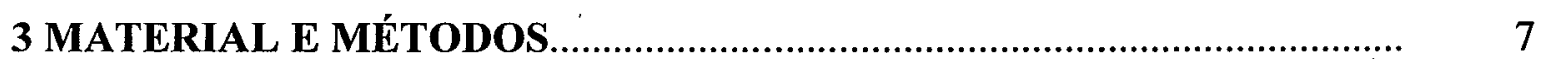

3.1 Caracterização da área experimental...................................................... 7

3.2 Tratamentos e delineamento experimental............................................. 9

3.3 Biossólido.................................................................................. 10

3.4 Monitoramento da fertilidade do solo.................................................. 11

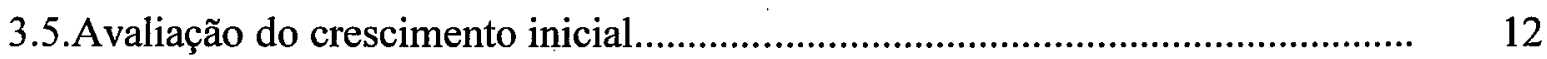

3.6. Concentração de nutrientes nas folhas....................................................... 12

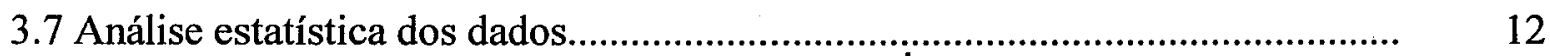

4 RESULTADOS E DISCUSSÃO............................................................. 13

4.1 Efeito do biossólido na fertilidade do solo e nutrição das árvores...................... 13

4.2 Curva de resposta à aplicação do biossólido............................................. 17

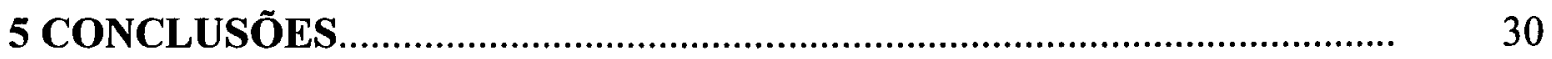

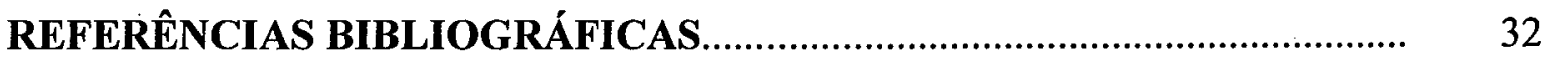




\section{LISTA DE FIGURAS}

Página

1 Precipitação e temperatura média mensal durante o período experimental (jul/98 a fev/99), e média de precipitação anual no intervalo de 1990 a 1996.

2 Atributos químicos do solo (média \pm erro padrão), camada $0-5 \mathrm{~cm}$, nas entrelinhas do povoamento (a) aos 6 meses e (b) aos 13 meses pós-aplicação do biossólido. Os valores representados por símbolos circulares referem-se às doses crescentes de biossólido, 0 a $40 \mathrm{t} \mathrm{ha}{ }^{-1}$, com suplementação de $\mathrm{K}$

3 Atributos químicos do solo (média \pm erro padrão), camada $0-5 \mathrm{~cm}$, nas entrelinhas do povoamento (a) aos 6 meses e (b) aos 13 meses pós-aplicação do biossólido. Os valores representados por símbolos circulares referem-se às doses crescentes de biossólido, 0 a $40 \mathrm{t} \mathrm{ha}^{-1}$, com suplementação de $\mathrm{K}$.

4 Micronutrientes no solo (média \pm erro padrão), camada $0-5 \mathrm{~cm}$, nas entrelinhas do povoamento (a) aos 6 meses e (b) aos 13 meses pós-aplicação do biossólido. Os valores representados por símbolos circulares referem-se às doses crescentes de biossólido, 0 a $40 \mathrm{t} \mathrm{ha}^{-1}$, com suplementação de $\mathrm{K}$.

5 Concentração foliar de macronutrientes (média \pm erro padrão) aos 12 e 24 meses de idade das plantas, 8 e 20 meses pós-aplicação do biossólido respectivamente, nos diferentes tratamentos

6 Concentração foliar de micronutrientes (média \pm erro padrão) aos 12 e 24 meses de idade das plantas, 8 e 20 meses pós-aplicação do biossólido respectivamente, nos diferentes tratamentos.

7 Curva de resposta à doses crescentes de biossólido, com suplementação de $\mathrm{K}$ (biossólido $+\mathrm{KCl}=165 \mathrm{~kg} \mathrm{ha}^{-1} \mathrm{de} \mathrm{K}$ ), respostas à aplicações de $10 \mathrm{t} \mathrm{ha}^{-1} \mathrm{de}$ biossólido sem suplementação de $\mathrm{K}$ e com suplementação de $\mathrm{K}$ e $\mathrm{P}$ e, resposta à fertilização mineral sem biossólido do povoamento de Eucalyptus grandis com a) 17 meses e b) 24 meses de idade. Nesta idade tinham transcorrido 13 e 20 meses pós-aplicação do biossólido, respectivamente. 


\section{LISTA DE TABELAS}

Página

1 Análise física do solo.

2 Alguns atributos químicos do solo por ocasião da instalação do experimento.

3 Atributos químicos (elementos totais, base seca- $65^{\circ} \mathrm{C}$ ) do biossólido tipo $\mathrm{B}$, produzido pela Estação de Tratamento de Esgoto de Barueri, SABESP/SP.

4 Atributos químicos do solo (média \pm erro padrão), camadas de 0-5, 5-10 e 10-20 $\mathrm{cm}$, nas entrelinhas do povoamento, seis meses após a aplicação do biossólido. Médias na mesma coluna e profundidade, seguidas de letras iguais não diferem entre si a $5 \%$ de significância pelo Teste de Tukey

5 Atributos químicos do solo (média \pm erro padrão), camadas de 0-5, 5-10 e 10-20 $\mathrm{cm}$, nas entrelinhas do povoamento, treze meses após a aplicação do biossólido. Médias na mesma coluna e profundidade, seguidas de letras iguais não diferem entre si a 5\% de significância pelo Teste de Tukey.

Micronutrientes do solo (média \pm erro padrão), camadas de 0-5, 5-10 e 10-20 cm, nas entrelinhas do povoamento, seis meses após a aplicação do biossólido. Médias na mesma coluna e profundidade, seguidas de letras iguais não diferem entre si a $5 \%$ de significância pelo Teste de Tukey

7 Teores de micronutrientes no solo (média \pm erro padrão), camadas de 0-5, 5-10 e $10-20 \mathrm{~cm}$, nas entrelinhas do povoamento, 13 meses após a aplicação do biossólido. Médias na mesma coluna e profundidade, seguidas de letras iguais não diferem entre si a 5\% de significância pelo Teste de Tukey. 


\title{
CRESCIMENTO INICIAL, FERTILIDADE DO SOLO E NUTRIÇÃO. MINERAL DE UM POVOAMENTO DE Eucalyptus grandis FERTILIZADO COM BIOSSÓLIDO.
}

\author{
Autor: LUCIANO MENDES SOUZA VAZ \\ Orientador: Prof. Dr. JOSÉ LEONARDO DE MORAES GONÇALVES
}

\section{RESUMO}

Com o objetivo de avaliar o efeito da aplicação de doses crescentes de biossólido $(5,10$, 15,20 e $40 \mathrm{t} \mathrm{ha}^{-1}$, base seca) na fertilidade do solo, crescimento e nutrição mineral de um povoamento de Eucalyptus grandis foi instalado um experimento na Estação Experimental de Itatinga da ESALQ/USP, Itatinga, SP (2300' LS, 48 52' LO e altitude de $750 \mathrm{~m}$ ). O solo da área foi caracterizado como um Latossolo Vermelho-Amarelo A moderado textura média. Seis meses pós-aplicação do biossólido, para todos tratamentos, não foram constatadas alterações do $\mathrm{pH}$ e dos teores de $\mathrm{P}, \mathrm{Mg}, \mathrm{Zn}, \mathrm{Cu}$ e B nas camadas de solo analisadas. Foi observada elevação dos teores de $\mathrm{K}, \mathrm{Ca}$ e $\mathrm{S}$, e redução das concentrações de $\mathrm{Al}, \mathrm{Fe}$ e $\mathrm{Mn}$, dependendo da dose de biossólido aplicada. Treze meses pós-aplicação do biossólido, foram constatadas elevação do $\mathrm{pH}$ e considerável elevação dos teores de $\mathrm{P}, \mathrm{Ca}, \mathrm{K}$ e S , somente, na camada 0-5 cm. Abaixo desta camada, só os teores de $\mathrm{S}$ elevaram-se. Para as duas épocas de amostragem do solo, com a elevação das doses de biossólido, ocorreu redução dos teores de MO, somente na camada 0-5 cm de solo. Em compasso com este efeito, os teores de $\mathrm{N}$ e $\mathrm{S}$ no tecido foliar elevaram-se. A disponibilidade de $\mathbf{P}$ assimilável elevou-se, consideravelmente, com o tempo de contato do biossólido com o solo, resultando em maior absorção de $\mathrm{P}$ e crescimento. A aplicação de fertilizante fosfatado no sulco ou cova de plantio, conjuntamente com o biossólido, mostrou-se necessária para elevar o crescimento inicial das plantas. A suplementação de $\mathrm{K}$ em plantações jovens de 
eucalipto poderá não ser necessária para doses de biossólido maiores que 10 t ha ${ }^{-1}$, quando as concentrações de $\mathrm{K}$ trocável forem médias. A elevação das doses de biossólido, de 0 a $40 \mathrm{t} \mathrm{ha}^{-1}$, resultou numa resposta quadrática em termos de produção de madeira. Aos vinte e quatro meses de idade, a aplicação de $10 \mathrm{t} \mathrm{ha}^{-1}$ de biossólido, com ou sem suplementação de $\mathrm{K}$, resultou num crescimento semelhante ao obtido com apenas aplicação de fertilização mineral. A resposta à aplicação de biossólido elevou-se com a idade, refletindo, principalmente, os efeitos benéficos devidos à elevação da disponibilidade de nutrientes para as árvores 


\title{
INITIAL GROWTH, SOIL FERTILITY AND MINERAL NUTRITION OF Eucalyptus grandis STANDS FERTILIZED WITH BIOSOLID
}

\author{
Author: LUCIANO MENDES SOUZA VAZ \\ Adviser: Prof. Dr. JOSÉ LEONARDO DE MORAES GONÇALVES
}

\section{SUMMARY:}

In order to evaluate the effect of growing rates of biosolid $(5,10,15,20$ and $40 t$ $\mathrm{ha}^{-1}$, dry base) in soil fertility, growth and mineral nutrition of Eucalyptus grandis stands was established a trial in the Itatinga Experimental Station of ESALQ/USP, Itatinga, SP $\left(23^{\circ} 00^{\prime} \mathrm{LS}, 48^{\circ} 52^{\prime} \mathrm{LO}\right.$ and altitude of $\left.750 \mathrm{~m}\right)$. The soil in the area was characterized as a Red-Yellow Latosol A moderate medium texture. Six months after application of the biosolid, for all treatments, changes of $\mathrm{pH}, \mathrm{P}, \mathrm{Mg}, \mathrm{Zn}, \mathrm{Cu}$ and $\mathrm{B}$ in the soil layers were not verified. Increasing of $\mathrm{K}, \mathrm{Ca}$ and $\mathrm{S}$, and reduction of $\mathrm{Al}, \mathrm{Fe}$ and $\mathrm{Mn}$ concentrations were verified. Thirteen months after application, increasing of $\mathrm{pH}$ and $\mathrm{P}, \mathrm{Ca}, \mathrm{K}$ and $\mathrm{S}$ concentrations were verified only in the layer $0-5 \mathrm{~cm}$. Below this layer, only $\mathrm{S}$ concentration increased. For the two sampling, with increasing of biosolid rates, reduction of organic matter content was verified at $0-5 \mathrm{~cm}$ soil layer. According to this effect, the $\mathrm{N}$ and $\mathrm{S}$ concentration in foliage increased. $\mathrm{P}$ available increased considerably with biosolid-soil contact time, resulting in higher uptake of $\mathbf{P}$ and growth. The application of $\mathrm{P}$ fertilizer in the furrow or planting hole simultaneously with spread biosolid on soil was shown necessary to elevate the initial growth of the plants. No K response was verified. For medium exchangeable $K$ concentration, $K$ fertilizer adding in young eucalypt plantations cannot be necessary for biosolid rates larger than $10 \mathrm{tha}^{-1}$. 
The increasing of biosolid rates from 0 to $40 \mathrm{tha}^{-1}$ resulted in a quadratic response of wood production. At 24 months of tree age, the application of $10 \mathrm{tha}^{-1}$ of biosolid, with or without $\mathrm{K}$ adding, resulted in a growth rate similar to the fertilized treatment. The response to the biosolid application increased with age, due mainly to beneficial effects of increasing nutrient availability for the trees. 


\section{INTRODUÇÃO}

Nos últimos anos o mundo vem assistindo à contaminação crescente dos recursos naturais, alertando a sociedade quanto à produção descontrolada de resíduos e aos seus possíveis tratamentos. Pesquisas cada vez mais específicas são realizadas com o intuito de encontrar soluções que contemplem políticas efetivas de minimização na produção e tratamento dos resíduos gerados. Um dos objetivos desta busca por soluções é uma disposição final adequada, que preze os princípios de conservação do ambiente, preservando os recursos naturais e dos ecossistemas nele inseridos.

As Estações de Tratamento de Esgoto (ETE) têm como função o tratamento biológico dos resíduos orgânicos com alto teor de umidade, produzidos pela população e indústrias, conhecidos como esgoto. Os processos de tratamento visam a degradação da carga orgânica contida nestes resíduos e a recuperação das águas servidas, tendo como produto final o lodo de esgoto ou biossólido. Como conceito para biossólido tem-se que são lodos resultantes do sistema de tratamento biológico de despejos líquidos, e que possuem características que o conferem a possibilidade de reciclagem (Companhia de Tecnologia e Saneamento Ambiental, 1999). A Estação de Tratamento de Barueri (Companhia de Saneamento Básico do Estado de São Paulo - SABESP) atende parte da cidade de São Paulo (Tsutya, 2000), produzindo cerca de $150 \mathrm{t} \mathrm{dia}^{-1}$ de biossólido (60\% de umidade), que são depositados diariamente no aterro sanitário Bandeirantes.

O potencial de uso do biossólido em plantações florestais, particularmente com espécies de Eucalyptus e Pinus, é muito grande. A fertilização de povoamentos florestais com biossólido, tem como ponto positivo, o fato de que os produtos destas culturas não são voltados para alimentação humana ou animal, diminuindo portanto os riscos de contaminação do homem. O potencial de uso do biossólido vem sendo 
relatado em áreas florestais, naturais e plantadas, nos Estados Unidos e vários países da Europa e Ásia. No Brasil, especificamente sobre este tema, as pesquisas são muito recentes e ainda em andamento.

O objetivo proposto por este trabalho foi avaliar o efeito de doses crescentes de biossólido, em relação à adubação mineral, quanto a fertilidade do solo crescimento e nutrição mineral de um povoamento de Eucalyptus grandis. 


\section{REVISÃO DE LITERATURA}

\subsection{Definição de lodo de esgoto e biossólido}

O lodo de esgoto tem a seguinte definição segundo à Associação Brasileira de Normas Técnicas (ABNT; NBR 10004, 1986): "Resíduos nos estados sólido e semisólido, que resultam da comunidade e origem industrial, doméstica, hospitalar, comercial, agrícola e de serviços de varrição. Ficam incluídos nesta definição os lodos provenientes de sistemas de tratamento de água, aqueles gerados em equipamentos e instalações de controle de poluição, bem como determinados líquidos cujas particularidades tornem inviável o seu lançamento na rede pública de esgoto ou corpos de água, ou exijam para isso soluções técnicas e economicamente viáveis face a melhor tecnologia disponível." A CETESB (1999), através de um manual técnico, denomina biossólido o lodo resultante do sistema de tratamento biológico de despejos líquidos, com características semelhantes àquelas contidas neste documento.

A Agência de Proteção Ambiental dos Estados Unidos (USEPA/ EUA), através de uma regulamentação (EPA, Part 503, 1995), define biossólido como sendo um produto sólido orgânico produzido por processos de tratamento dos esgotos municipais e que pode ser reciclado. Por convenção, o termo biossólido foi aceito pela comunidade científica brasileira, para designar o lodo de esgoto doméstico que tenha passado por uma decomposição microbiológica parcial e que seja passível de utilização, sem criar nenhum impacto negativo ao meio. 


\subsection{Potencial de uso do biossólido em plantações florestais}

O Brasil possui cerca de 5 milhões de hectares reflorestados com eucaliptos (65\%) e pinus (35\%). No Estado de São Paulo, a área florestada abrange 790 mil hectares (70\% de eucalipto e 30\% de pinus) (ANFPC, 1995). A grande maioria dos solos usados para fins de florestamentos apresentam avançado estágio de intemperização, sendo de baixa fertilidade. O material de origem mais comum nesses solos são as rochas sedimentares, principalmente os arenitos, com baixa disponibilidade de minerais primários. Os minerais de argila na maioria desses solos são basicamente óxidos de Fe e Al, caulinita e materiais amorfos. Com essa composição mineralógica, as reservas de nutrientes na forma de minerais primários são pequenas, a capacidade de troca de cátions é baixa, a capacidade de fixação de $\mathrm{P}$ é média a alta, a permeabilidade e o potencial de lixiviação de bases dos solos é muito elevado. Os teores de macro e micronutrientes são considerados baixos ou muito baixoṣ, com grandes implicações sobre os potenciais de uso e manejo dos solos (Gonçalves et al., 1997). Sob tais condições, as colheitas sucessivas de madeira de espécies com grande capacidade de extração de nutrientes, como o eucalipto e o pinus, têm grande impacto sobre as baixas disponibilidades e reservas minerais dos solos. Isso frequentemente reflete em quedas de produtividade, porque a reposição de nutrientes via fertilização mineral é menor do que a exportação de nutrientes via madeira (Gonçalves et al., 2000b).

Visando avaliar as melhorias nas propriedades físicas do solo com a aplicação do biossólido, vários estudos foram realizados, mostrando o potencial do resíduo como agente recondicionador de solos (Andreoli et al., 1997a; Ayuso et al., 1996; Phillips et al., 1986; Riekerk, 1981; Silva et al., 1995; Sort \& Alcañiz, 1999; Weber \& Shames, 1984 e Zhang \& Xue, citados por Wang, 1997). A utilização do biossólido pode resultar em melhoras significativas nas propriedades químicas do solo, afetando de maneira positiva a fertilidade. São relatados aumentos no $\mathrm{pH}$, matéria orgânica, CTC, concentração de macronutrientes, principalmente os íons N, P e Ca (Andreoli et al., 1997b; Ayuso et al., 1996; Berton et al., 1989; Bevacqua \& Mellano, 1994; Deus et al., 1996; Dutch \& Wosltenholme, 1994; Fiskell et al., 1990; Folle et al., 1995; Luca et al., 
1996; Melo et al., 1994; Miyazawa et al., 1999; Oliveira et al., 1995; Phillips et al., 1986; Riekerk, 1981; Shimp et al., 1996; Silva et al., 1997; Skousen \& Klinger, 1998; Sui \& Thompson, 2000; Tsutya, 2000 e Zhang \& Xue, citados por Wang, 1997).

A avaliação do biossólido como fertilizante orgânico na produtividade de culturas agrícolas anuais e perenes tem sido realizada por diversos pesquisadores em diferentes partes do mundo (Bowler, 1998; Deschamps \& Favaretto, 1999; Hansen \& Jorgensen, 1991; Henry et al., 1994; Sims, 1996; Tsutya, 2000 e Wang, 1997). No Brasil vários trabalhos foram realizados em áreas agrícolas com resultados promissores (Berton et al., 1989; Defelipo et al.,1991; Deschamps \& Sales, 1996; Melo et al., 1994 e Oliveira et al., 1995).

De modo geral, na Europa, Ásia, América do Norte e Austrália, existem registros de respostas favoráveis das espécies florestais de interesse silvicultural à aplicação de biossólido. Dentre os efeitos da aplicação do biossólido são relatados: aumentos significativos no diâmetro e altura das árvores, disponibilização de nutrientes, (principalmente de $\mathrm{N}, \mathrm{P}, \mathrm{Ca}$ e $\mathrm{K}$ ), aumento na produtividade do sítio florestal e na biomassa (Dutch et al.,1994; McNab \& Barry, 1985; Phillips et al., 1986; Weetman et al., 1993; McDonald et al., 1994; Henry et al., 1994; Polglase \& Myers, 1995; Harrison et al., 1996; Zhang \& Xue, citados por Wang, 1997 e Riddel- Black et al., 2000).

A fertilização de povoamentos florestais com biossólido, tem como ponto positivo, o fato de que os produtos destas culturas não são voltados para alimentação humana ou animal, diminuindo os riscos de contaminação do homem. Contudo, cuidados especiais devem ser tomados em relação a localização, forma e dose de aplicação do lodo, para não ocorrer a contaminação do solo, nascentes, cursos de água e lençóis freáticos (Gonçalves et al., 2000a).

O potencial de aplicação de biossólido em áreas florestais é grande, em função das seguintes razões: a) As florestas ocupam extensas áreas e eventuais diminuições no uso de fertilizantes minerais podem constituir substanciais reduções de custos na produção florestal; b) Amplas áreas florestais sofrem de deficiências ou desbalanços nutricionais, especialmente $\mathrm{N}$ e $\mathrm{P}$. A carência de nutrição adequada é um dos principais fatores limitantes da produtividade florestal em todo mundo; c) As áreas florestais, de 


\section{MATERIAL E MÉTODOS}

\subsection{Caracterização da área experimental}

As pesquisas foram conduzidas na Estação Experimental de Itatinga,

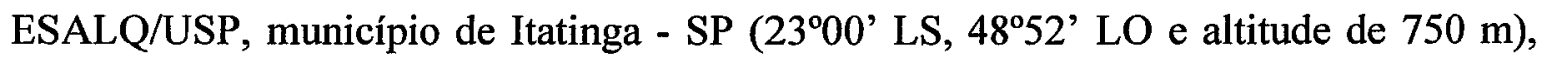
distando aproximadamente $220 \mathrm{~km}$ da cidade de São Paulo e $170 \mathrm{~km}$ da cidade de Piracicaba - SP. O tipo de solo ocorrente na área é caracterizado como um Latossolo Vermelho-Amarelo, textura média (areia $=830$, silte $=50 \mathrm{e}$ argila $=120 \mathrm{~g} \mathrm{~kg}^{-1}$ na camada 0-20 cm), distrófico, relevo plano. Nas Tabelas 1 e 2 são apresentados alguns atributos químicos e físicos do solo. A vegetação natural da região é o cerrado, sendo as condições edafoclimáticas e florísticas da mesma representativas de extensos blocos de florestas homogêneas plantadas no planalto ocidental paulista.

Tabela 1. Análise física* do solo.

\begin{tabular}{cccccc}
\hline Profundidade & \multicolumn{3}{c}{ Areia } & Silte & Argila \\
\cline { 2 - 4 } & Areia grossa & Areia fina & Total & & \\
\hline cm & 532 & 241 & 773 & 59 & 168 \\
$0-30$ & 495 & 266 & 761 & 49 & 190 \\
$30-60$ & 496 & 278 & 774 & 29 & 197 \\
$60-90$ & 496 &
\end{tabular}

* Análise realizada segundo metodologia apresentada por Camargo et al. (1986). 
Tabela 2. Alguns atributos químicos* do solo por ocasião da instalação do experimento.

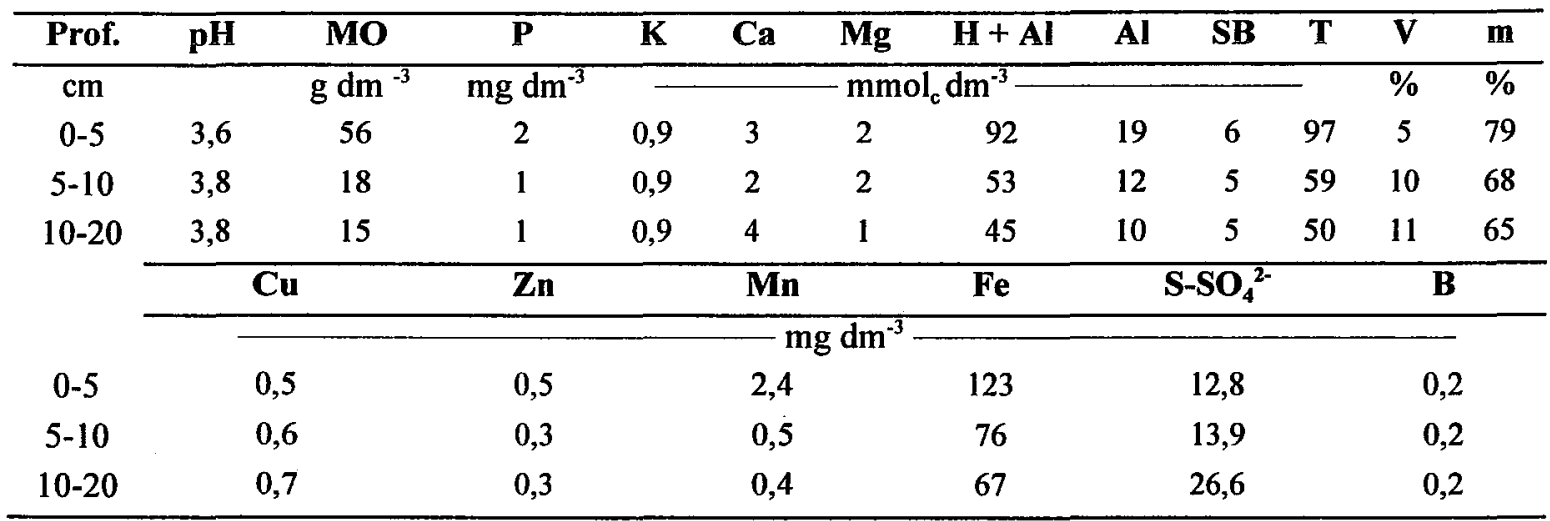

*Análise realizada segundo metodologia apresentada por Raij et al. (1987).

O clima da região é caracterizado como $\mathrm{Cwa}$, segundo a classificação de Köeppen, ou seja, mesotérmico de inverno seco, em que a temperatura média do mês mais frio (julho) é inferior a $18^{\circ} \mathrm{C}$, e a do mês mais quente (janeiro), superior a $22^{\circ} \mathrm{C}$. A precipitação média anual da área é de, aproximadamente, $1600 \mathrm{~mm}$, com $57 \%$ concentrada nos meses de dezembro a março. Não há déficit hídrico.

Os dados pluviométricos, de temperatura máxima, média e mínima, e de umidade relativa, durante o período de condução do experimento (Figura 1), foram coletados numa estação meteorológica situada na Estação Experimental.

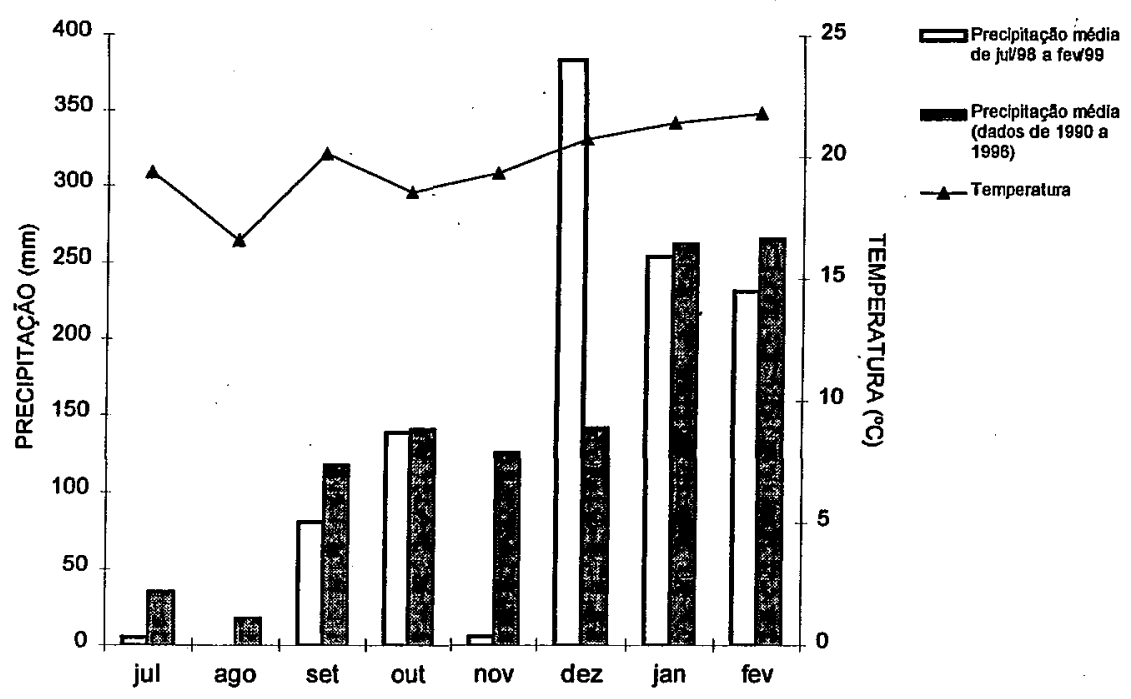

Figura 1. Precipitação e temperatura média mensal durante o periodo experimental (jul/98 a fev/99), e média de precipitação anual entre 1990 a 1996. 


\subsection{Tratamentos e delineamento experimental}

Os tratamentos foram os seguintes:

1. Testemunha absoluta - sem adubação e sem aplicação de biossólido;

2. Adubação mineral - $1,5 \mathrm{t} \mathrm{ha}^{-1}$ de calcário dolomítico (a lanço em área total), $110 \mathrm{~kg}$ $\mathrm{ha}^{-1}$ de 0-45-0 (sulco de plantio), $150 \mathrm{~kg} \mathrm{ha}^{-1}$ de 10-20-10 (sulco de plantio), $80 \mathrm{~kg} \mathrm{ha}^{-1} \mathrm{de}^{-1}$ 20-0-20 (45 dias pós-plantio aplicado em meia lua ao redor da muda), $180 \mathrm{~kg} \mathrm{ha}^{-1} \mathrm{de} 16-$ $0-32+0,3 \% \mathrm{~B}+0,5 \%$ de $\mathrm{Zn}$ (6 meses pós plantio aplicado numa faixa de $40 \mathrm{~cm}$ na entrelinha de plantio) e $240 \mathrm{~kg} \mathrm{ha}^{-1}$ de 16-0-32 + 0,3\% B + 0,5\% de $\mathrm{Zn}$ (12 meses pósplantio aplicado numa faixa de $40 \mathrm{~cm}$ na entrelinha de plantio);

3. $05 \mathrm{t} \mathrm{ha}^{-1}$ de biossólido (base seca), com suplementação de $\mathrm{K}$;

4. 10 tha $^{-1}$ de biossólido (base seca), sem suplementação de $\mathrm{K}$;

5. $10 \mathrm{t} \mathrm{ha}^{-1}$ de biossólido (base seca), com suplementação de $\mathrm{K}$;

6. $10 \mathrm{t} \mathrm{ha}^{-1}$ de biossólido (base seca), com suplementação de $\mathrm{K}$ e P (sulco de plantio);

7. $15 \mathrm{t} \mathrm{ha}^{-1}$ de biossólido (base seca), com suplementação de $\mathrm{K}$;

8. 20 t ha ${ }^{-1}$ de biossólido (base seca), com suplementação de $\mathrm{K}$;

9. $40 \mathrm{t} \mathrm{ha}^{-1}$ de biossólido (base seca), com suplementação de K;

$\mathrm{Na}$ instalação do experimento os tratamentos $3,5,6,7,8$ e 9 receberam suplementação de $\mathrm{K}\left(\mathrm{KCl}, 60 \%\right.$ de $\left.\mathrm{K}_{2} \mathrm{O}\right)$, até que as quantidades de $\mathrm{K}$ contidas no biossólido somada às do fertilizante potássico ficassem iguais a do tratamento $2(125 \mathrm{~kg}$ ha $^{-1}$ de K). O tratamento 6 recebeu suplementação de $\mathrm{P}$ (superfosfato triplo), de modo que a quantidade de $\mathrm{P}$ contida no biossólido mais a do fertilizante fosfatado ficasse igual a do tratamento $2\left(80 \mathrm{~kg} \mathrm{ha}^{-1}\right.$ de $\mathrm{P}_{2} \mathrm{O}_{5}$ ). Em meados de Julho de 1998 , foi feita a aplicação de biossólido, em faixas ( $2 \mathrm{~m}$ de largura), nas entrelinhas, $50 \mathrm{~cm}$ distante das linhas de plantio. A suplementação de $\mathrm{K}$ foi feita parceladamente, em até três vezes. A primeira parcela de $\mathrm{KCl}, 35 \mathrm{~kg} \mathrm{ha}^{-1}$ de $\mathrm{K}_{2} \mathrm{O}$, foi aplicada em meia lua ao redor das plantas, seis meses pós-plantio; a segunda, $58 \mathrm{~kg} \mathrm{ha}^{-1}$ de $\mathrm{K}_{2} \mathrm{O}$, e terceira parcelas é restante, foram 
tratamento que recebe e a concentração de coliformes fecais, esse biossólido é classificado como do tipo B (CETESB, 1999); apresenta densidade de coliformes fecais inferior a $2 \times 10^{-6} \mathrm{NMP}_{\mathrm{g} \mathrm{ST}}{ }^{-1}$ (Número Mais Provável por grama de Sólidos Totais). É um resíduo orgânico (30\% de matéria orgânica em média), umidade em torno de $60 \%$, pH próximo a 11. Observam-se elevados teores de N, P, Ca, Fe, Zn e S.

Tabela 3. Atributos químicos (elementos totais, base seca $-65^{\circ} \mathrm{C}$ ) do biossólido tipo $\mathrm{B}$ produzido pela Estação de Tratamento de Esgoto de Barueri, SABESP/SP.

\begin{tabular}{lclc}
\hline Elemento & Concentração & Elemento & Concentração \\
\hline $\mathrm{C}\left(\mathrm{g} \mathrm{kg}^{-1}\right)$ & 114,0 & $\mathrm{~S}\left(\mathrm{~g} \mathrm{~kg}^{-1}\right)$ & 6,0 \\
$\mathrm{~N}\left(\mathrm{~g} \mathrm{~kg}^{-1}\right)$ & 26,6 & $\mathrm{Fe}\left(\mathrm{mg} \mathrm{kg}^{-1}\right)$ & 39200 \\
$\mathrm{Relação} \mathrm{C:N}$ & 4,3 & $\mathrm{Zn}\left(\mathrm{mg} \mathrm{kg}^{-1}\right)$ & 1500 \\
$\mathrm{P}\left(\mathrm{g} \mathrm{kg}^{-1}\right)$ & 9,5 & $\mathrm{Mn}\left(\mathrm{mg} \mathrm{kg}^{-1}\right)$ & 300 \\
$\mathrm{~K}\left(\mathrm{~g} \mathrm{~kg}^{-1}\right)$ & 1,3 & $\mathrm{Cd}\left(\mathrm{mg} \mathrm{kg}^{-1}\right)$ & 21 \\
$\mathrm{Ca}\left(\mathrm{g} \mathrm{kg}^{-1}\right)$ & 95,0 & $\mathrm{~Pb}\left(\mathrm{mg} \mathrm{kg}^{-1}\right)$ & 200 \\
$\mathrm{Mg}\left(\mathrm{g} \mathrm{kg}^{-1}\right)$ & 3,0 & $\mathrm{Umidade} \%)$ & 60 \\
$\mathrm{Na}\left(\mathrm{g} \mathrm{kg}^{-1}\right)$ & 0,5 & $\mathrm{pH}$ & 10,6 \\
\hline
\end{tabular}

\subsection{Monitoramento da fertilidade do solo}

As características químicas do solo foram determinadas para as camadas de 0-5, 5-10, 10-20 cm de profundidade, avaliando-se os seguintes parâmetros: $\mathrm{pH}$, Carbono Orgânico, $\mathrm{P}, \mathrm{Ca}, \mathrm{Mg}, \mathrm{K}, \mathrm{S}$ e Al trocáveis, $\mathrm{H}+\mathrm{Al}$, Soma de Bases (SB), Capacidade de Troca Catiônica (T), segundo metodologia descrita por Raij et al. (1987). Os micronutrientes $(\mathrm{B}, \mathrm{Cu}, \mathrm{Fe}, \mathrm{Mn}$ e $\mathrm{Zn}$ ) foram analisados segundo a metodologia descrita por Lindsay \& Norvell (1978).

Para a amostragem de solo, foram coletadas 10 amostras simples em um transecto diagonal na área útil da parcela, compreendendo uma faixa de $2 \mathrm{~m}$ de largura no centro das entrelinhas, onde foi aplicado o biossólido. Estas amostras originaram uma amostra composta, que foi seca em estufa de circulação forçada de ar $\left(45^{\circ} \mathrm{C}\right)$ até apresentarem o seu peso constante. Em seguida foram peneiradas em malha de $2 \mathrm{~mm}$. As amostragens e determinações químicas foram feitas aos seis e 13 meses pós-aplicação do biossólido na área. 


\subsection{Avaliação do crescimento inicial}

$\mathrm{O}$ crescimento em altura, o diâmetro à altura do peito (DAP) e a sobrevivência das árvores foram avaliados semestralmente. A partir da medições realizadas nos $36 \mathrm{~m}^{2}$ centrais de cada parcela foi derrubada uma árvore, com o diâmetro à altura do peito (DAP) médio, na bordadura, para as avaliações de volume sólido de madeira o qual foi estimado pela fórmula de Smallian:

$\mathrm{VT}=\left(\mathrm{T}^{2}+\mathrm{B}^{2}\right) \times \mathrm{L} \times \mathrm{C}$, onde VT = volume total do tronco $\left(\mathrm{m}^{3}\right) ; \mathrm{L}=$ comprimento de cada segmento do tronco onde mediu-se a espessura $(\mathrm{m}) ; \mathrm{T}=$ raio do topo do tronco $(\mathrm{cm}) ; \mathrm{B}=$ raio da base do tronco $(\mathrm{cm})$ e $\mathrm{C}=0,0001570796$ (constante).

\subsection{Concentração de nutrientes nas folhas}

$\mathrm{Na}$ área útil de cada parcela, foram coletadas seis folhas no terço superior de dez árvores escolhidas aleatoriamente, originando uma amostra composta. $\mathrm{O}$ processamento das amostras e análises de macro e micronutrientes seguiram as metodologias descritas por Malavolta et al. (1997). Estes procedimentos foram repetidos aos 12 e 24 meses pósplantio.

\subsection{Análise estatísitica dos dados}

Para testar possíveis diferenças entre as médias dos tratamentos avaliados quanto aos atributos químicos do solo e concentrações foliares foi utilizada a análise de variância (ANOVA). Uma vez detectada diferença utilizou-se posteriormente o Teste de Tukey para a comparação das médias. Os dados relativos ao crescimento das árvores foram submetidos à analise de regressão, utilizando-se o software Sigma Plot 4.0 (Jandel Scientific). Como variável dependente foi utilizado o volume sólido de madeira e, variável independente, as doses crescentes de biossólido. 


\section{RESULTADOS E DISCUSSÃO}

\subsection{Efeito do biossólido na fertilidade do solo e nutrição das árvores}

Seis meses pós-aplicação do biossólido em faixas $(2 \mathrm{~m})$, nas entrelinhas de plantio do eucalipto, sem incorporação, não foram constatadas alterações do pH e dos teores de $\mathrm{P}, \mathrm{Mg}, \mathrm{Zn}, \mathrm{Cu}$ e $\mathrm{B}$ nas camadas analisadas. Foi observada elevação dos teores de $\mathrm{K}, \mathrm{Ca}$ e $\mathrm{S}$, e tendência ou redução das concentrações de matéria orgânica (MO), $\mathrm{Al}$, Fe e Mn (Tabelas 4 e 5; Figuras 2, 3 e 4). Aos 13 meses pós-aplicação, foram constatadas consideráveis elevações do $\mathrm{pH}$ e dos teores de $\mathrm{P}, \mathrm{Ca}, \mathrm{K}$ e S na camada 0-5 $\mathrm{cm}$. Os teores de $\mathrm{Ca}, \mathrm{Zn}$ e $\mathrm{Cu}$ foram maiores com doses de $5 \mathrm{a} 10 \mathrm{t} \mathrm{ha} \mathrm{h}^{-1}$, decrescendo a partir da dose de $15 \mathrm{t} \mathrm{ha}^{-1}$. Os teores de $\mathrm{MO}, \mathrm{B}$ e $\mathrm{Mn}$, para a maioria dos tratamentos, não sofreram alterações. Abaixo desta camada, só os teores de S elevaram-se, aos seis e 13 meses pós-aplicação do biossólido (Tabelas 5 e 7; Figuras 2, 3 e 4).

Para as duas épocas de amostragem do solo, com a elevação das doses de biossólido, ocorreu redução dos teores de MO. As maiores reduções foram observadas aos seis meses pós-aplicação para as maiores doseș: 20 e $40 \mathrm{t} \mathrm{ha}^{-1}$ (Figura 2). Segundo Stevenson (1986), a adição de material orgânico ao solo pode estimular a decomposição de húmus, devido ao aumento da atividade microbiana. As maiores reduções nos primeiros meses pós-aplicação devem estar associadas às maiores disponibilidades de frações de $\mathrm{C}$ facilmente decomponíveis.

Em compasso com a mineralização da $\mathrm{MO}$ no solo, os teores de $\mathrm{N}$ e $\mathrm{S}$ no tecido foliar elevaram-se com o aumento das doses de biossólido em ambas as épocas de 
amostragem (Figura 5). Provavelmente, devido a maior absorção de $\mathrm{N}$ e $\mathrm{S}$ proveniente da mineralização do N-orgânico do biossólido e da MO do solo. A maior absorção e assimilação de $\mathrm{N}$ é aceita como uma das principais causas da resposta em crescimento das árvores às doses crescentes de biossólido (Figura 7). No estágio juvenil, até aproximadamente 24 meses, período em que ocorre a expansão da área foliar e sistema radicular, a demanda de $\mathrm{N}$ é muito elevada (Gonçalves et al., 2000b). A adição deste nutriente, principalmente em solos com baixo teor de matéria orgânica, resulta em acréscimos no nível de crescimento. Geralmente, este efeito só perdura até o fechamento de copas. Depois, a competição por luz e água passam a constituir fatores mais limitantes ao crescimento das árvores, e o suprimento de $\mathrm{N}$ via mineralização da matéria orgânica do solo e ciclagem de nutrientes atende a demanda das árvores (Barros \& Novais, 1990; Gonçalves et al., 2000b e Gonçalves et al., 1997). Ainda que não resulte em elevações na produtividade de madeira no fim do ciclo, este maior crescimento inicial das árvores, provavelmente, causado pelo aumento da disponibilidade de $\mathrm{N}$, é muito desejável, pois reduz os custos de controle de plantas invasoras.

Seis meses pós-aplicação do biossólido, não foi constatada alteração dos teores de $\mathrm{P}$ na camada $0-5 \mathrm{~cm}$. De forma diferente, sete meses após, foi constatada considerável elevação dos teores de P: os teores elevaram-se de $6 \mathrm{mg} \mathrm{dm}^{-3}$, na testemunha, a $25 \mathrm{mg}$ $\mathrm{dm}^{-3}$, no tratamento que recebeu $40 \mathrm{t} \mathrm{ha}^{-1}$. de biossólido (Tabelas 4 e 6; Figura 2). Diversos trabalhos relatam aumentos na concentração de $\mathrm{P}$ no solo após a aplicação de biossólido (Berton, 1989; Dutch \& Wosltenholme, 1994; Folle et al., 1995; Martins et al., 1997 Oliveira et al., 1995; Phillips et al., 1986; Sui \& Thompson, 2000 e Wang, 1997)., devido a mineralização do P-orgânico contido neste produto (Tedesco et al., 1992 e Tsai \& Rosseto, 1992). Refletindo o efeito da disponibilização de P assimilável com o tempo de contato do biossólido com o solo, todos os tratamentos que receberam biossólido, com ou sem suplementação de $P$, não resultaram em alterações da concentração foliar deste nutriente aos 12 meses de idade, oito meses pós-aplicação do biossólido. No tratamento que recebeu apenas fertilização mineral (tratamento 2), o teor de $\mathrm{P}$ foi consideravelmente elevado e o teor de $\mathrm{Zn}$ reduzido, evidenciando a pronta 
disponibilidade do $\mathrm{P}$ e o antagonismo de absorção destes dois nutrientes (Malavolta, 1997) (Figuras 5 e 6). Por outro lado, aos 24 meses de idade, 20 meses pós-aplicação do biossólido, os teores foliares de $\mathrm{P}$ de todos tratamentos que receberam biossólido, com ou sem suplementação de $\mathrm{P}$, foram maiores do que os obtidos nas plantas do tratamento testemunha (Figura 5), indicando maior absorção de P. As concentrações de P nestes tratamentos ficaram dentro da faixa considerada adequada para o eucalipto, 0,9 a $1,3 \mathrm{~g}$ $\mathrm{kg}^{-1}$ (Gonçalves et al., 1996), indicando que, nessa idade, o $P$ não deve estar constituindo um nutriente limitante para o crescimento das plantas.

A aplicação de $10 \mathrm{tha}^{-1}$ de biossólido, sem suplementação de $\mathrm{K}$, elevou o teor deste nutriente de 0,8 (testemunha) para $1,1 \mathrm{mmol}_{\mathrm{c}} \mathrm{dm}^{-3}$ de solo, seis meses após a aplicação, na camada de $0-5 \mathrm{~cm}$ (tratamento 4) (Tabela 4 e Figura 2), atingindo a faixa de concentração considerada adequada para o crescimento de eucalipto (Gonçalves et al., 1996). Esses resultados evidenciam que a suplementação de $\mathrm{K}$ em plantações de eucalipto poderá não ser necessária para doses de biossólido maiores que $10 \mathrm{t} \mathrm{ha}^{-1}$, quando as concentrações de $\mathrm{K}$ trocável forem médias $\left(0,08\right.$ a $\left.0,10 \mathrm{mmol}_{c} \mathrm{dm}^{-3}\right)$. Neste caso, somente o $\mathrm{K}$ disponível do biossólido elevaria a fertilidade do solo a níveis suficientes para atender a demanda do eucalipto, que é bem inferior ao da maioria das culturas agrícolas (Raij et al., 1996). Sete meses após, a concentração do K no solo decresceu de 0,8 para $0,3 \mathrm{mmol}_{\mathrm{c}} \mathrm{dm}^{-3}$ na testemunha e, 1,1 para $0,4 \mathrm{mmol}_{\mathrm{c}} \mathrm{dm}^{-3}$ no tratamento 4, devido, principalmente, a absorção e lixiviação de $K$ (Tabela 6 e Figura 2).

As concentrações foliares de $\mathrm{K}$ foram semelhantes para todos tratamentos que receberam aplicações de biossólido, com ou sem sưplementação de K. Por outro lado, a concentração de $\mathrm{K}$ na testemunha, o menos produtivo, foi muito superior a estes tratamentos (Figura 5). Uma das causas prováveis para esta constatação é o "efeito diluição", ou seja, apesar das plantas possuírem maior conteúdo de $\mathrm{K}$ em sua biomassa foliar, ele dilui-se nesta biomassa, resultando em menor concentração deste nutriente.

Aos seis meses pós-aplicação do biossólido, apenas no tratamento $9\left(40 \mathrm{t} \mathrm{ha}^{-1}\right)$ houve considerável elevação $(0,7$ unidade) do $\mathrm{pH}$ no solo, embora não significativa (Tabela 4 e Figura 2). Na avaliação posterior (13 meses), não foram verificadas 
diferenças entre tratamentos, embora os erros padrões das médias tenham sido bem maiores; apenas nos tratamentos que receberam biossólido (Tabela 4 e Figura 2), refletindo a maior variabilidade espacial. Alguns autores (Berton et al., 1989; Martins et al. 1997 e Phillips et al., 1986), têm relatado aumentos de $\mathrm{pH}$ no solo em tratamentos em que o biossólido é incorporado ao solo. Quando este experimento foi planejado, supondo que o elevado $\mathrm{pH}$ e concentração de $\mathrm{Ca}$ do biossólido pudessem ser prejudiciais ao crescimento inicial das mudas, optou-se por sua aplicação em faixas nas entrelinhas de plantio. Diante dos resultados obtidos, supõe-se que a aplicação do biossólido a lanço ou em faixas, sobre as linhas de plantio, sem incorporação, não deva causar injúrias ou desbalanços nutricionais às mudas devido a este problema.

Houve nítida elevação da concentração de $\mathrm{Ca}$ no solo nos tratamentos que receberam biossólido, maior que no tratamento que só recebeu fertilização mineral, 13 meses pós-aplicação (Tabela 3). As alterações foram pequenas seis meses pós-aplicação (Tabela 4 e Figura 2). Este aumento do teor de Ca está associado à sua alta concentração no biossólido, $95 \mathrm{~g} \mathrm{~kg}^{-1}$ (Tabela 3), originada no processo de tratamento deste resíduo com cal extinta $(\mathrm{CaO})$, para higienização e adensamento do produto. A utilização deste tipo de biossólido como fonte de $\mathrm{Ca}$ tem sido preconizada por vários autores (Berton, 1989; Melo \& Marques, 2000; Phillips, 1986 e Tsutya, 2000). A elevação da concentração de Ca trocável no solo resultou em maior absorção deste nutriente, com valores crescentes com o aumento da dose de biossólido (Figura 5). Em função desses resultados, deduz-se que, com a aplicação de doses iguais ou maiores do que $10 \mathrm{t} \mathrm{ha}^{-1}$ de biossólido, a suplementação de Ca via calagem ou outras fontes é dispensável. Isto tem forte implicação econômica e técnica no manejo de plantações de eucaliptos, porque esta cultura demanda e exporta grandes quantidades de $\mathrm{Ca}$, além disso, há grandes extensões de solo empobrecidos pela exportação de Ca, após sucessivas colheitas de madeira, sem reposição via calagem (Gonçalves et al., 2000b).

Quanto aos decréscimos das disponibilidades de $\mathrm{Cu}, \mathrm{Zn}$ e $\mathrm{Mn}$ no solo (Tabelas 5 e 7; Figura 3), com o aumento da dose de biossólido, supõe-se que sejam, em grande parte, devidas às reações precipitações ocasionadas pelas mudanças de $\mathrm{pH}$ e formação de 
complexos polidentados (quelatos) com os componentes húmicos do solo e/ou adsorção pelas frações minerais ou orgânicas do solo (Barros et al., 1990; Illera et al., 2000; Mello et al., 1989; Miyazawa et al., 1999; Sposito, 1989 e Tisdale et al., 1985).

Caso a incorporação do biossólido fosse realizada, provavelmente as alterações dos atributos relativos à fertilidade do solo seriam maiores, devido a maior solubilização e reação do biossólido no solo. Contudo, a incorporação de resíduos culturais ou outros insumos não tem sido praticada na maioria dos grandes empreendimentos florestais. Atualmente, tem sido amplamente recomendado o cultivo mínimo do solo, com intuito de prevenir sua degradação física, química e biológica, que não prevê revolvimento do solo (Gonçalves et al., 2000b).

\subsection{Curva de resposta à aplicação de biossólido}

A elevação das doses de biossólido, de 0 a $40 \mathrm{t} \mathrm{ha}^{-1}$, resultou numa resposta quadrática em termos de produtividade de madeira com casca (Figura 7). Aos 17 meses de idade, 13 meses pós-aplicação do biossólido, o crescimento em volume elevou-se de 1,9 para 7,2 $\mathrm{m}^{3} \mathrm{ha}^{-1}$, quando se compara a testemunha com o tratamento que recebeu $40 \mathrm{t}$ $\mathrm{ha}^{-1}$. Este efeito é atribuído, principalmente, ao biossólido. Por exemplo, a aplicação de $10 \mathrm{t} \mathrm{ha}^{-1}$ de biossólido, sem suplementação de $\mathrm{K}$ (tratamento 4), resultou num crescimento semelhante àquele obtido com esta mesma dose, com suplementação de $\mathrm{K}$. Como discutido anteriormente, a aplicação desta dose de biossólido, com ou sem

suplementação de $\mathrm{K}$, elevou os níveis de $\mathrm{K}$ do solo, os quais ficaram dentro da faixa considerada adequada para esta cultura. Isto evidencia que a disponibilidade de $\mathrm{K}$ no biossólido pode ser suficiente para o crescimento do eucalipto, pelo menos na fase juvenil. Aos 24 meses de idade, a aplicação de $10 \mathrm{t} \mathrm{ha}^{-1}$ de biossólido, com ou sem suplementação de $\mathrm{K}$, resultou num crescimento semelhante ao obtido com apenas aplicação de fertilização mineral. 
Comparando o crescimento das árvores nas duas idades, constata-se que a resposta à aplicação de biossólido eleva-se com a idade, refletindo, principalmente, efeitos benéficos devidos à elevação da disponibilidade de nutrientes, oriundos da solubilização e mineralização de componentes deste resíduo, bem como a um maior volume de exploração do solo pelas raízes, o que aumenta o acesso a esses nutrientes. Esses efeitos refletiram-se numa maior absorção de nutrientes (Figura 7).

$\mathrm{O}$ tratamento que recebeu $10 \mathrm{t} \mathrm{ha}^{-1}$ biossólido mais suplementação de $\mathrm{P}$ (tratamento 6) foi o que resultou em maior resposta, tanto aos 17 como aos 24 meses de idade. O crescimento foi $139 \%$ e $32 \%$ superior àquele obtido no tratamento $5\left(10 \mathrm{tha}^{-1}\right.$ de biossólido mais K, sem suplementação de P), respectivamente, nestas idades (Figura 7). Comumente, em plantações de eucaliptos, sobretudo no estágio juvenil de crescimento (primeiros dois anos), quando ocorre a expansão da área foliar, a fertilização fosfatada tem sido a mais responsiva e usada. Este efeito é atribuído às baixas concentrações de P nos solos usados para fins de florestamento, abaixo do nível crítico, como no presente estudo. $\mathrm{O}$ nível crítico de $\mathrm{P}$ no solo para o eucalipto decresce exponencialmente com o tempo de crescimento das árvores, sendo bastante elevado na fase de mudas (Novais et al., 1982). Por causa disto, a aplicação do fertilizante fosfatado em plantações de eucalipto tem sido realizada no sulco de plantio, com intuito de aumentar a eficiência de aproveitamento do fertilizante, bem como prover às mudas maior disponibilidade de $\mathbf{P}$ junto às raízes, suprindo suas elevadas demandas iniciais. Pelo menos duas razões principais podem ser apontadas para a não resposta ao $\mathrm{P}$ contido (9,5 $\mathrm{g} \mathrm{kg}^{-1}$, Tabela 3) no biossólido: (i) o $\mathrm{P}$ está presente em formas não ou lentamente disponíveis e (ii) a aplicação do biossólido foi superficial, nas entrelinhas, a $0,5 \mathrm{~m}$ das linhas de plantio, portanto, distante das raízes, o que dificultou sua absorção.

O maior crescimento do tratamento que recebeu biossólido mais suplementação de P na base (sulco de plantio), indica que esta é uma alternativa potencial para elevar as respostas às aplicações desse resíduo em plantações de eucalipto. Os custos com a aplicação do biossólido devem ser equiparados ou superados com os benefícios advindos do aumento de produtividade e com a economia de fertilizantes, sobretudo as fontes de 
$\mathrm{N}, \mathrm{Ca}, \mathrm{Zn}$ e B. Em outros biossólidos, obtidos a partir de processos que originam produtos com menor $\mathrm{pH}$ e teor de $\mathrm{Fe}$ (sem ou com menor uso de cal e cloreto de $\mathrm{Fe}$ ), a disponibilidade de $\mathrm{P}$ para as árvores pode ser maior, reduzindo a demanda de suplementação com fertilizantes fosfatados.

O tratamento 2, que recebeu fertilização mineral, foi $27 \%$ inferior ao tratamento 6 (10 t ha ${ }^{-1}$ de biossólido $+\mathrm{K}$ e P) aos 17 meses (Figura 7). Ou seja, este percentual de acréscimo de produtividade no tratamento 6 é atribuido a outras propriedades do biossólido, que não aos efeitos dos nutrientes K e P. Aparentemente, a disponibilização e maior absorção de $\mathrm{N}$ sejam as causas principais (Figura 5). 
Tabela 4. Atributos químicos* do solo (média \pm erro padrão), camadas de 0-5, 5-10 e 10-20 cm; nas entrelinhas do povoamento, seis meses após a aplicação do biossólido. Médias na mesma coluna e profundidade, seguidas de letras iguais não diferem entre si a $5 \%$ de significância pelo Teste de Tukey.

\begin{tabular}{|c|c|c|c|c|c|c|c|c|c|c|c|}
\hline Prof & $\overline{\mathrm{pH}}$ & MO & $\bar{P}$ & $\bar{K}$ & $\mathbf{C a}$ & $\overline{\mathrm{Mg}}$ & $\overline{H+A l}$ & $\overline{\text { AI }}$ & SB & $T$ & $\mathrm{~S}-\mathrm{SO}_{4}{ }^{2-}$ \\
\hline $\mathbf{c m}$ & & $\mathrm{g} \mathrm{dm}^{-3}$ & $\mathrm{mg} \mathrm{dm}$ & & & & $-\mathrm{mmol}_{\mathrm{c}} \mathrm{o}$ & & & & $\mathrm{mg} \mathrm{dm}$ \\
\hline \multicolumn{12}{|c|}{ 1. Testemunha } \\
\hline $0-5$ & $3,6(0)$ & $43(8)$ & $2 \mathrm{a}(0,5)$ & $0,8(0)$ & $2 \mathrm{~b}(0)$ & $2(0,5)$ & $92(11,5)$ & $20(2)$ & $6 \mathrm{~b}(1)$ & $80(12)$ & $17 \mathrm{~b}(1,5)$ \\
\hline $5-10$ & $3,8(0)$ & $18(2)$ & $1(0)$ & $0,9(0)$ & $4(1,5)$ & $2(0,5)$ & $54(2,5)$ & $12(0,5)$ & $6 \mathrm{ab}(1,5)$ & $59(3)$ & $20 c(0,6)$ \\
\hline $10-20$ & $3,8(0)$ & $16(1)$ & $1(0)$ & $0,9(0)$ & $4(0,5)$ & $1(0)$ & $45(2,5)$ & $10(0,5)$ & $6(0,5)$ & $50(2,5)$ & $29 \mathrm{~cd}(0,4)$ \\
\hline \multicolumn{12}{|c|}{ 2. Adubação Mineral } \\
\hline $0-5$ & $3,5(0)$ & $42(6,5)$ & $1 \mathrm{~b}(0)$ & $1,0(0)$ & $4 b(1)$ & $2(0,5)$ & $94(17)$ & $19(3)$ & $6 \mathrm{~b}(1)$ & $101(16)$ & 18 b $(2,9)$ \\
\hline $5-10$ & $3,9(0)$ & $28(8)$ & $1(0)$ & $1,0(0)$ & $2(0,5)$ & $1(0)$ & $58(4)$ & $12(0,5)$ & $4 \mathrm{ab}(0,5)$ & $62(4)$ & $20 \mathrm{c}(2,7)$ \\
\hline $10-20$ & $3,8(0)$ & $16(2)$ & $1(0)$ & $0,9(0)$ & $2(0,5)$ & $1(0)$ & $45(4)$ & $9(1)$ & $4(0,5)$ & $49(4)$ & $23 \mathrm{~cd}(2,3)$ \\
\hline \multicolumn{12}{|c|}{ 3. $5 \mathrm{t} \mathrm{ha}^{-1}$ de bios. $+K$} \\
\hline $0-5$ & $3,8(0)$ & $44(7,5)$ & $2 a b(1)$ & $1,0(0)$ & $3 \mathrm{~b}(0,5)$ & $2(0,5)$ & $78(18,5)$ & $13(3)$ & $6 \mathrm{~b}(1)$ & $84(19)$ & $21 \mathrm{~b}(1,4)$ \\
\hline $5-10$ & $3,9(0)$ & $20(1)$ & $2(0,5)$ & $1,0(0)$ & $4(1)$ & $1(0)$ & $52(3)$ & $10(1)$ & $5 \mathrm{ab}(1)$ & $57(3)$ & $27 \mathrm{c}(0,2)$ \\
\hline $10-20$ & $3,8(0)$ & $16(0,5)$ & $1(0)$ & $1,0(0)$ & $2(0,5)$ & $1(0)$ & $45(1)$ & $9(0,5)$ & $4(0,5)$ & $49(1)$ & 33 bcd $(0,3)$ \\
\hline \multicolumn{12}{|c|}{ 4. $10 \mathrm{tha}^{-1}$ de bios. } \\
\hline $0-5$ & $3,7(0)$ & $27(3,5)$ & $1 \mathrm{ab}(4)$ & $1,1(0)$ & $4 \mathrm{~b}(0,5)$ & $2(0,5)$ & $64(3,5)$ & $13(2)$ & $7 \mathrm{~b}(0,5)$ & $70(3,5)$ & $28 \mathrm{~b}(1,6)$ \\
\hline $5-10$ & $3,9(0)$ & $16(1)$ & $1(0)$ & $0,9(0)$ & $2(0,5)$ & $1(0)$ & $46(0,5)$ & $10(0,5)$ & $4 \mathrm{~b}(0,5)$ & $49(1)$ & $39 c(0,7)$ \\
\hline $10-20$ & $3,8(0)$ & $13(1)$ & $1(0)$ & $1,0(0)$ & $2(0,5)$ & $1(0)$ & $41(3)$ & $9(0)$ & $4(0,5)$ & $45(3,5)$ & 57 bcd $(0,5)$ \\
\hline \multicolumn{12}{|c|}{ 5. $10 \mathrm{t} \mathrm{ha}^{-1}$ de bios. $+\mathrm{K}$} \\
\hline $0-5$ & $4,0(0)$ & $54(1,5)$ & $I b(1)$ & $1,1(0)$ & $4 \mathrm{~b}(0,5)$ & $2(0,5)$ & $69(13)$ & $13(3,5)$ & $8 \mathrm{~b}(0,5)$ & $77(13)$ & $45 \mathrm{ab}(1,2)$ \\
\hline $5-10$ & $3,7(0)$ & $29(8)$ & $4(2,5)$ & $1,0(0)$ & $4(1)$ & $1(0,5)$ & $61(1 \mathrm{I})$ & $14(2,5)$ & $5 a b(1)$ & $68(10)$ & $58 \mathrm{bc}(1,6)$ \\
\hline $10-20$ & $3,8(0)$ & $18(1,5)$ & $2(1)$ & $0,9(0)$ & $6(2,5)$ & $2(1)$ & $51(2)$ & $11(1)$ & $8(3)$ & $59(3,5)$ & $71 \mathrm{abc}(0,9)$ \\
\hline \multicolumn{12}{|c|}{$6.10 \mathrm{t} \mathrm{ha}^{-1}$ de bios. + KP } \\
\hline $0-5$ & $3,8(0)$ & $35(6)$ & $1 \mathrm{ab}(0)$ & $1,1(0)$ & $4 \mathrm{~b}(2)$ & $1(0,2)$ & $84(12)$ & $14(4)$ & $7 \mathrm{~b}(2,5)$ & $90(11)$ & $21 \mathrm{~b}(0,9)$ \\
\hline $5-10$ & $3,8(0)$ & $18(2)$ & $1(0)$ & $1,2(0)$ & $3(1)$ & $1(0)$ & $58(5)$ & $12(1)$ & 5 ab (1) & $62(4,5)$ & $41 \mathrm{c}(0,2)$ \\
\hline $10-20$ & $3,8(0)$ & $15(1)$ & $1(0)$ & $1,0(0)$ & $2(0,5)$ & $1(0)$ & $56(4,5)$ & $11(2)$ & $4(0,5)$ & $60(4)$ & $50 \mathrm{~cd}(0,2)$ \\
\hline \multicolumn{12}{|c|}{$7.15 \mathrm{t} \mathrm{ha}^{-1}$ de bios. $+\mathrm{K}$} \\
\hline $0-5$ & $3,8(0)$ & $50(12)$ & $1 \mathrm{~b}(0)$ & $1,2(0)$ & $4 \mathrm{~b}(1)$ & $2(0,4)$ & $94(24)$ & $13(9)$ & $8 b(1,5)$ & $101(2)$ & $42 \mathrm{ab}(0,8)$ \\
\hline $5-10$ & $3,8(0)$ & $23(3,5)$ & $1(0)$ & $0,9(0)$ & $4(1,5)$ & $2(0,5)$ & $66(3,5)$ & $12(1)$ & $7 \mathrm{ab}(1,5)$ & $72(4,5)$ & 51 bc $(0,6)$ \\
\hline $10-20$ & $3,8(0)$ & $14(2)$ & $1(0)$ & $1,0(0)$ & $2(0,5)$ & $2(0,5)$ & $52(1)$ & $10(2)$ & $5(0,5)$ & $58(6)$ & 66 bcd $(0,7)$ \\
\hline \multicolumn{12}{|c|}{$8.20 \mathrm{tha}^{-1}$ de bios. $+K$} \\
\hline $0-5$ & $4,0(1)$ & $31(5)$ & $2 a b(1)$ & $1,0(0)$ & $5 \mathrm{~b}(0,5)$ & $2(3)$ & $40(8)$ & $11(3)$ & $8 \mathrm{~b}(0,5)$ & $66(3)$ & $74 \mathrm{a}(1)$ \\
\hline $5-10$ & $3,8(0)$ & $18(1)$ & $1(0)$ & $0,9(0)$ & $8(2,5)$ & $2(0)$ & $54(5,5)$ & $10(1,5)$ & $10 \mathrm{a}(2,5)$ & $64(2,5)$ & $80 \mathrm{ab}(0,8)$ \\
\hline $10-20$ & $3,8(0)$ & $17(1,5)$ & $1(0)$ & $1,0(0)$ & $4(0,5)$ & $1(0,5)$ & $56(3,5)$ & $11(1)$ & $5(1)$ & $61(2)$ & $95 \mathrm{ab}(0,6)$ \\
\hline \multicolumn{12}{|c|}{ 9. $40 \mathrm{t} \mathrm{ha}^{-1}$ de bios. $+\mathrm{K}$} \\
\hline $0-5$ & $4,3(1)$ & $30(1)$ & $2 \mathrm{ab}(1)$ & $0,9(0)$ & $11 \mathrm{a}(1,5)$ & $2(0)$ & $66(19,5)$ & $9(3)$ & 15 a $(0,5)$ & $80(5)$ & $74 \mathrm{a}(1,1)$ \\
\hline $5-10$ & $4,3(1)$ & $21(4)$ & $1(1)$ & $1,7(0)$ & $8(1,5)$ & $2(0)$ & $47(10,5)$ & $8(2,5)$ & $10 a b(1)$ & $56(31)$ & $108 \mathrm{a}(0,7)$ \\
\hline $10-20$ & $3,8(1)$ & $17(0,5)$ & $1(0)$ & $1,1(0)$ & $4(0,5)$ & $2(0)$ & $44(6,5)$ & $8(2,5)$ & $7(0)$ & $50(1,5)$ & 113 a $(0,6)$ \\
\hline
\end{tabular}

*Análise realizada segundo metodologia apresentada por Raij et al. (1987). 
Tabela 5. Micronutrientes do solo* (média \pm erro padrão), camadas de 0-5, 5-10 e 10-20 cm, nas entrelinhas do povoamento, seis meses após a aplicação do biossólido. Médias na mesma coluna e profundidade, seguidas de letras iguais não diferem entre si a $5 \%$ de significância pelo Teste de Tukey.

\begin{tabular}{|c|c|c|c|c|c|}
\hline Prof & $\mathbf{C u}$ & $\mathbf{Z n}$ & $\mathbf{M n}$ & $\mathbf{F e}$ & $\bar{B}$ \\
\hline $\mathbf{c m}$ & & & $-m g d m^{-3}-$ & & $=$ \\
\hline \multicolumn{6}{|c|}{ 1. Testemunha } \\
\hline $0-5$ & $0,5(0)$ & $0,5(0)$ & 2,5 a (08) & $130,2 \mathrm{ab}(11,9)$ & $0,22(0,2)$ \\
\hline $5-10$ & $0,6(0)$ & $0,3(0)$ & $0,9(0,2)$ & $74,8(4,9)$ & $0,17(0,1)$ \\
\hline $10-20$ & $0,7(0)$ & $0,3 \mathrm{ab}(0)$ & $0,5(0,1)$ & $66,5(3,3)$ & $0,17(0,1)$ \\
\hline \multicolumn{6}{|c|}{ 2. Adubação química } \\
\hline $0-5$ & $0,6(0)$ & $0,5(0)$ & 1,4 ab $(0,5)$ & 141,2 a $(22,9)$ & $0,19(0,1)$ \\
\hline $5-10$ & $0,6(0,1)$ & $0,3(0)$ & $0,7(0,2)$ & $92,0(22)$ & $0,16(0,1)$ \\
\hline $10-20$ & $0,7(0)$ & $0,2 \mathrm{ab}(0)$ & $0,4(0)$ & $79,8(18,1)$ & $0,16(0)$ \\
\hline \multicolumn{6}{|c|}{$3.5 \mathrm{tha}^{-1}$ de bios. $+K$} \\
\hline $0-5$ & $0,8(0,1)$ & $1,1(0,3)$ & $1,3 \mathrm{ab}(0,3)$ & $120,0 \mathrm{abc}(11,3)$ & $0,17(0)$ \\
\hline $5-10$ & $0,8(0)$ & $0,5(0,1)$ & $0,6(0,1)$ & $80,2(2)$ & $0,15(0)$ \\
\hline $10-20$ & $0,8(0)$ & 0,3 a $(0,1)$ & $0,4(0)$ & $67,0(2,5)$ & $0,13(0)$ \\
\hline \multicolumn{6}{|c|}{ 4. $10 \mathrm{t} \mathrm{ha}^{-1}$ de bios. } \\
\hline $0-5$ & $0,7(0,1)$ & $0,8(0,4)$ & $0,9 \mathrm{ab}(0,2)$ & $105,5 \mathrm{abc}(13)$ & $0,17(0)$ \\
\hline $5-10$ & $0,7(0)$ & $0,2(0)$ & $0,6(0)$ & $73,5(5,6)$ & $0,14(0)$ \\
\hline $10-20$ & $0,7(0)$ & 0,2 ab (0) & $0,4(0)$ & $68,0(4,4)$ & $0,08(0)$ \\
\hline \multicolumn{6}{|c|}{ 5. $10 \mathrm{t} \mathrm{ha}^{-1}$ de bios $+K$} \\
\hline $0-5$ & $0,7(0,1)$ & $2,5(1,1)$ & $1,6 \mathrm{ab}(0,3)$ & $103,0 \mathrm{abc}(9,2)$ & $0,14(0)$ \\
\hline $5-10$ & $0,7(0)$ & $0,5(0,1)$ & $0,7(0,2)$ & $75,8(12,7)$ & $0,15(0)$ \\
\hline $10-20$ & $0,7(0)$ & $0,2 \mathrm{ab}(0)$ & $0,4(0,1)$ & $64,2(7,2)$ & $0,12(0)$ \\
\hline \multicolumn{6}{|c|}{ 6. $10 \mathrm{t} \mathrm{ha}^{-1}$ de bios. $+\mathrm{KP}$} \\
\hline $0-5$ & $0,6(0)$ & $0,5(0,2)$ & $1,0 \mathrm{ab}(0,2)$ & 83,2 bc $(7,1)$ & $0,16(0)$ \\
\hline $5-10$ & $0,7(0,1)$ & $0,2(0,1)$ & $0,6(0,1)$ & $59,5(2)$ & $0,14(0)$ \\
\hline $10-20$ & $0,6(0,1)$ & 0,1 b (0) & $0,8(0,4)$ & $57,2(2)$ & $0,11(0)$ \\
\hline \multicolumn{6}{|c|}{7.15 t ha $^{-1}$ de bios. $+K$} \\
\hline $0-5$ & $0,6(0,2)$ & $1,7(1,3)$ & 1,6 ab $(0,8)$ & 87,8 abc (6) & $0,19(0)$ \\
\hline $5-10$ & $0,6(0,1)$ & $0,3(0,1)$ & $0,6(0,1)$ & $64,2(4,6)$ & $0,18(0)$ \\
\hline $10-20$ & $0,6(0,1)$ & $0,1 \mathrm{~b}(0)$ & $0,4(0)$ & $49,5(5,4)$ & $0,10(0)$ \\
\hline \multicolumn{6}{|c|}{$8.20 \mathrm{tha}^{-1}$ de bios. $+\mathrm{K}$} \\
\hline $0-5$ & $0,7(0,1)$ & $0,3(0,5)$ & $0,4 \mathrm{~b}(0,4)$ & $72,5 \mathrm{c}(7,6)$ & $0,18(0)$ \\
\hline $5-10$ & $0,7(0)$ & $0,2(0,1)$ & $0,4(0)$ & $62,5(6,6)$ & $0,12(0)$ \\
\hline $10-20$ & $0,6(0)$ & 0,2 ab $(0)$ & $0,4(0)$ & $56,2(4,4)$ & $0,11(0)$ \\
\hline \multicolumn{6}{|c|}{$9.40 \mathrm{t} \mathrm{ha}^{-1}$ de bios. $+K$} \\
\hline $0-5$ & $0,7(0)$ & $0,8(0)$ & $1,4 \mathrm{ab}(0,3)$ & 79,5 bc $(8,7)$ & $0,18(0)$ \\
\hline $5-10$ & $0,7(0)$ & $0,5(0)$ & $0,8(0,2)$ & $56,5(5,9)$ & $0,13(0)$ \\
\hline $10-20$ & $0,7(0)$ & $0,2 a b(0)$ & $0,5(0,2)$ & $48,8(11)$ & $0,11(0)$ \\
\hline
\end{tabular}

* Análise realizada segundo metodologia apresentada por Lindsay \& Norvell (1978). 
Tabela 6. Atributos químicos do solo* (média \pm erro padrão), camadas de 0-5, 5-10 e 10-20 cm, nas entrelinhas do povoamento, treze meses após a aplicação do biossólido. Médias na mesma coluna e profundidade, seguidas de letras iguais não diferem entre si a $5 \%$ de significância pelo Teste de Tukey.

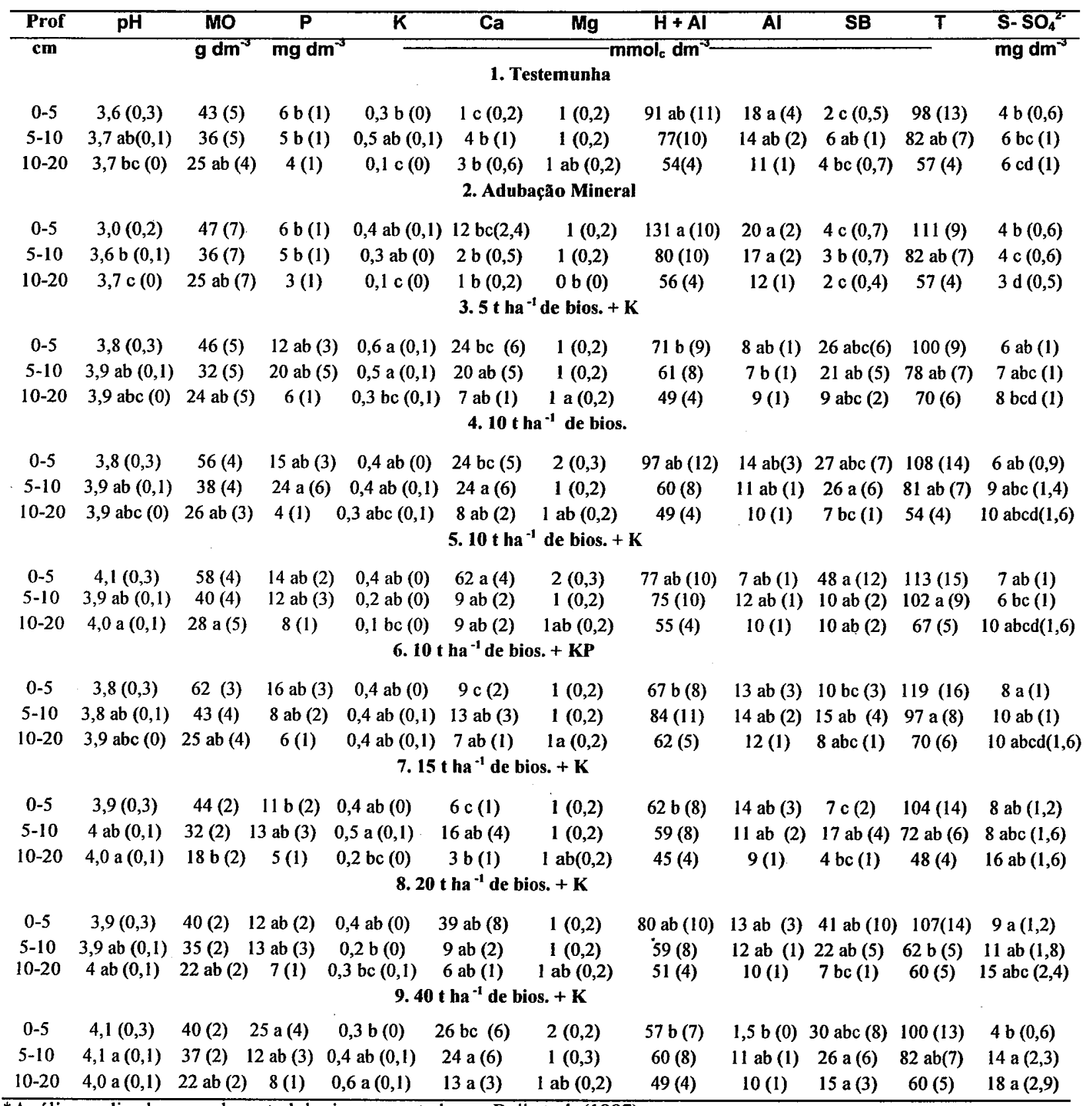

*Análise realizada segundo metodologia apresentada por Raij et al. (1987). 
Tabela 7. Micronutrientes no solo* (média \pm erro padrão), camadas de 0-5, 5-10 e 10-20 cm, nas entrelinhas do povoamento, treze meses após a aplicação do biossólido. Médias na mesma coluna e profundidade, seguidas de letras iguais não diferem entre si a $5 \%$ de significância pelo Teste de Tukey.

\begin{tabular}{|c|c|c|c|c|c|}
\hline Prof & $\mathbf{C u}$ & $\overline{\mathbf{Z n}}$ & $\overline{\mathbf{M n}}$ & $\overline{\mathbf{F e}}$ & $\overline{\mathbf{B}}$ \\
\hline $\mathrm{cm}$ & & & $-\mathbf{m g ~ d m}=$ & & \\
\hline \multicolumn{6}{|c|}{ 1. Testemunha } \\
\hline $0-5$ & 0,8 bc $(0,1)$ & $0,2 \mathrm{~b}(0,1)$ & $1,2 \mathrm{~b}(0,1)$ & $155,0(18)$ & $0,2 \mathrm{a}(0)$ \\
\hline $5-10$ & $1,0(0,1)$ & $0,2 \mathrm{c}(0)$ & $1,4(0,2)$ & $103,9(9)$ & $0,3(0)$ \\
\hline $10-20$ & 1,4 a $(0,1)$ & $0,4 \mathrm{~b}(0,1)$ & $0,6 \mathrm{bc}(0,1)$ & $93,0(12)$ & $0,1(0)$ \\
\hline \multicolumn{6}{|c|}{ 2. Adubação química } \\
\hline $0-5$ & 1,0 abc $(0,2)$ & 0,5 b $(0,1)$ & $1,6 \mathrm{~b}(0,2)$ & $122,6(14)$ & $0,2 \mathrm{ab}(0)$ \\
\hline $5-10$ & $1,0(0,1)$ & $0,3 \mathrm{c}(0)$ & $1,7(0,2)$ & $92,9(6)$ & $0,2(0)$ \\
\hline $10-20$ & $1,0 \mathrm{ab}(0,1)$ & $0,2 b(0)$ & 1,7 a $(0,2)$ & $99,0(12)$ & $0,2(0)$ \\
\hline \multicolumn{6}{|c|}{ 3. $5 \mathrm{t} \mathrm{ha}^{-1}$ de bios. $+K$} \\
\hline $0-5$ & $1,9 a b(0,3)$ & 4,6 a $(1,3)$ & $2,3 \mathrm{~b}(0,3)$ & $138,0(16)$ & $0,1 \mathrm{ab}(0)$ \\
\hline $5-10$ & $1,6(0,2)$ & 0,9 bc $(0,1)$ & $1,3(0,2)$ & $93,7(8)$ & $0,2(0)$ \\
\hline $10-20$ & $1,2 \mathrm{ab}(0,1)$ & $0,9 \mathrm{ab}(0,2)$ & 0,5 bc $(0,1)$ & $74,0(9)$ & $0,2(0)$ \\
\hline \multicolumn{6}{|c|}{$4.10 \mathrm{t} \mathrm{ha}^{-1}$ de bios. } \\
\hline $0-5$ & $1,5 \mathrm{ab}(0,3)$ & $2,6 \mathrm{ab}(0,7)$ & $2,3 \mathrm{~b}(0,3)$ & $139,0(16)$ & $0,2 \mathrm{a}(0)$ \\
\hline $5-10$ & $1,5(0,1)$ & 3,1 a $(0,5)$ & $1,7(0,2)$ & $101,0(9)$ & $0,2(0)$ \\
\hline $10-20$ & $1,1 a b(0,1)$ & $0,8 \mathrm{ab}(0,2)$ & $0,7 \mathrm{bc}(0,1)$ & $76,1(9)$ & $0,2(0)$ \\
\hline \multicolumn{6}{|c|}{5.10 tha $^{-1}$ de bios. $+K$} \\
\hline $0-5$ & 2,2 a $(0,4)$ & $3,5 \mathrm{ab}(1,0)$ & $0,9 b(0,1)$ & $125,3(15)$ & 0,3 a $(0)$ \\
\hline $5-10$ & $1,2(0,1)$ & $\mathrm{I}, 7 \mathrm{~b}(0,3)$ & $1,3(0,2)$ & $146,4(13)$ & $0,2(0)$ \\
\hline $10-20$ & $1,1 \mathrm{ab}(0,1)$ & $1,5 \mathbf{a}(0,3)$ & 1,1 ab $(0,2)$ & $102,7(13)$ & $0,2(0)$ \\
\hline \multicolumn{6}{|c|}{ 6. 10 t ha $^{-1}$ de bios. + KP } \\
\hline $0-5$ & $1,2 \mathrm{abc}(0,2)$ & $2,5 \mathrm{ab}(0,7)$ & 6,1 a $(0,7)$ & $173,6(20)$ & 0,2 a $(0)$ \\
\hline $5-10$ & $1,2(0,1)$ & 0,9 bc $(0,1)$ & $1,4(0,2)$ & $130,1(11)$ & $0,1(0)$ \\
\hline $10-20$ & $1,0 \mathrm{ab}(0,1)$ & $0,3 \mathrm{~b}(0,1)$ & 0,7 bc $(0,1)$ & $102,4(13)$ & $0,2(0)$ \\
\hline \multicolumn{6}{|c|}{7.15 t ha $^{-1}$ de bios. $+K$} \\
\hline $0-5$ & $1,0 \mathrm{abc}(0,2)$ & $2,0 \mathrm{~b}(0,6)$ & $2,0 \mathrm{~b}(0,2)$ & $179,0(21)$ & 0,2 a $(0)$ \\
\hline $5-10$ & $1,1(0,1)$ & $1,8 b(0,3)$ & $1,6(0,2)$ & $101,6(9)$ & $0,2(0)$ \\
\hline $10-20$ & 0,9 b $(0,1)$ & $0,4 \mathrm{~b}(0,1)$ & $0,4 c(0,1)$ & $72,2(9)$ & $0,2(0)$ \\
\hline \multicolumn{6}{|c|}{$8.20 \mathrm{t} \mathrm{ha}^{-1}$ de bios. $+\mathrm{K}$. } \\
\hline $0-5$ & $1,0 \mathrm{abc}(0,2)$ & $2,0 \mathrm{ab}(0,6)$ & $1,7 \mathrm{~b}(0,2)$ & $160,0(19)$ & $0,2 \mathrm{a}(0)$ \\
\hline $5-10$ & $1,0(0,1)$ & 1,3 bc $(0,2)$ & $1,3(0,2)$ & $111,2(1)$ & $0,2(0)$ \\
\hline $10-20$ & $1,0 \mathrm{ab}(0,1)$ & $0,7 \mathrm{ab}(0,1)$ & 0,7 bc $(0,1)$ & $62,4(8)$ & $0,1(0)$ \\
\hline \multicolumn{6}{|c|}{$9.40 \mathrm{t} \mathrm{ha}^{-1}$ de bios. $+\mathrm{K}$} \\
\hline $0-5$ & $0,16 \mathrm{c}(0)$ & $2,6 \mathrm{ab}(0,7)$ & $1,5 \mathrm{~b}(0,2)$ & $136,3(16)$ & $0,0(0)$ \\
\hline $5-10$ & $1,4(0,1)$ & $1,8 \mathrm{~b}(0,3)$ & $0,8(0,1)$ & $116,3(10)$ & $0,2(0)$ \\
\hline $10-20$ & 1,0 ab $(0,1)$ & $0,7 \mathrm{~b}(0,1)$ & $0,4 \mathrm{c}(0,1)$ & $88,9(11)$ & $0,2(0)$ \\
\hline
\end{tabular}

*Análise realizada segundo metodologia apresentada por Lindsay \& Norvell (1978). 

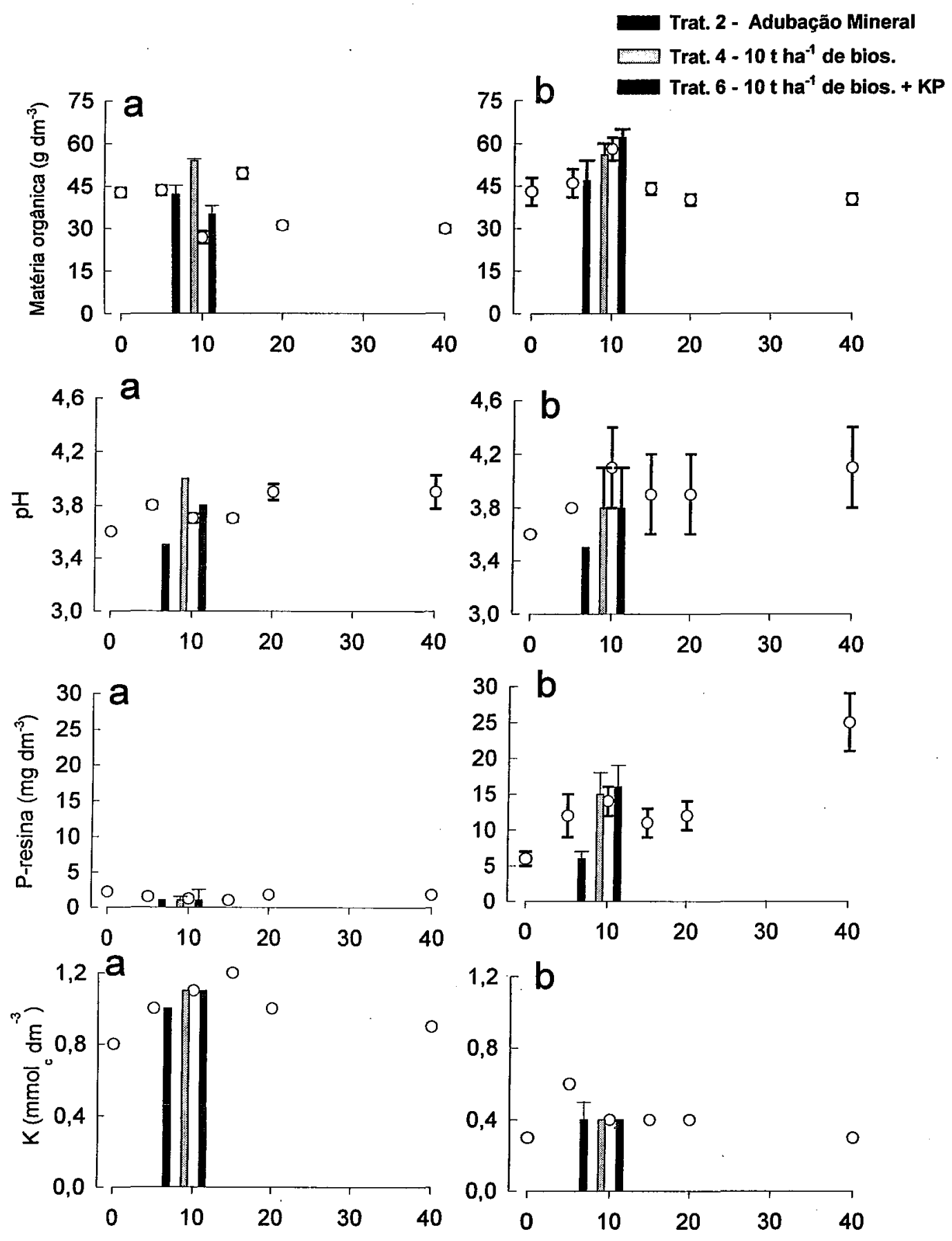

DOSE DE BIOSSÓLIDO (t ha-1)

Figura 2. Atributos químicos do solo (média \pm erro padrão), camada $0-5 \mathrm{~cm}$, nas entrelinhas do povoamento: a) aos seis meses e b) aos 13 meses pós-aplicação do biossólido. Os valores representados por símbolos circulares referem-se às doses crescentes de biossólido, 0 a $40 \mathrm{t}$ $\mathrm{ha}^{-1}$, com suplementação de $\mathrm{K}$. 
Trat. 2 - Adubação Mineral

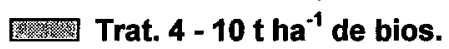

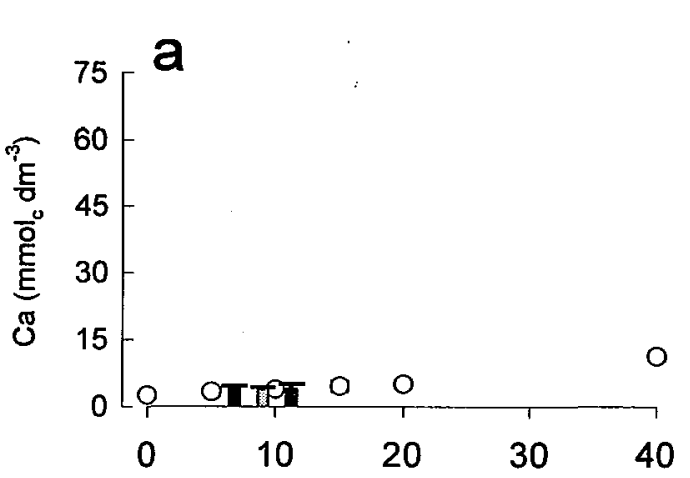

Trat. 6 - 10 t ha $^{-1}$ de bios. + PK
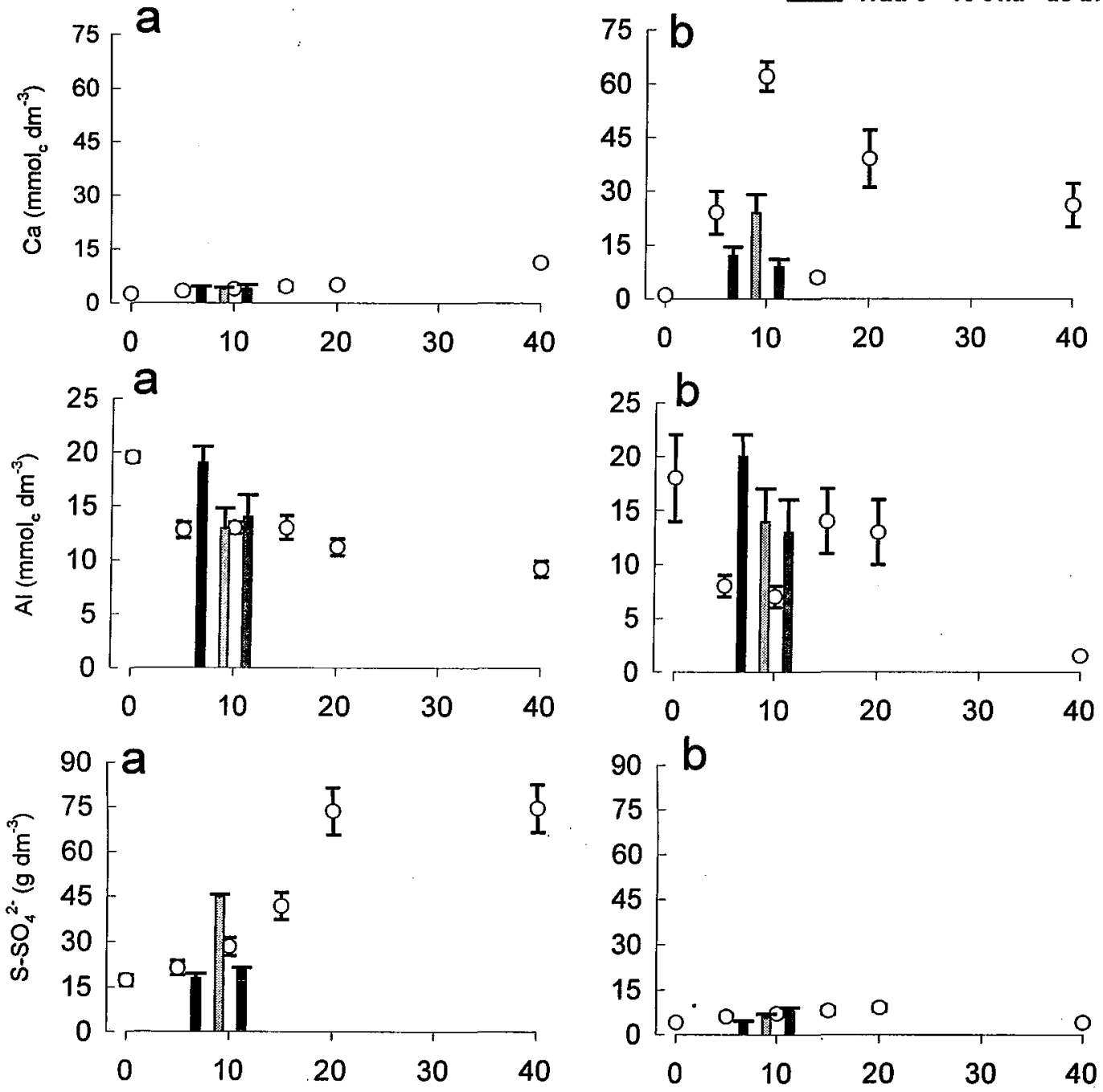

DOSE DE BIOSSÓLIDO (t ha $\left.\mathrm{a}^{-1}\right)$

Figura 3. Atributos químicos do solo (média \pm erro padrão), camada $0-5 \mathrm{~cm}$, nas entrelinhas do povoamento: a) aos seis meses e b) aos 13 meses pós-aplicação do biossólido. Os valores representados por símbolos circulares referem-se às doses crescentes de biossólido, 0 a $40 \mathrm{t}$ $\mathrm{ha}^{-1}$, com suplementação de $\mathrm{K}$. 

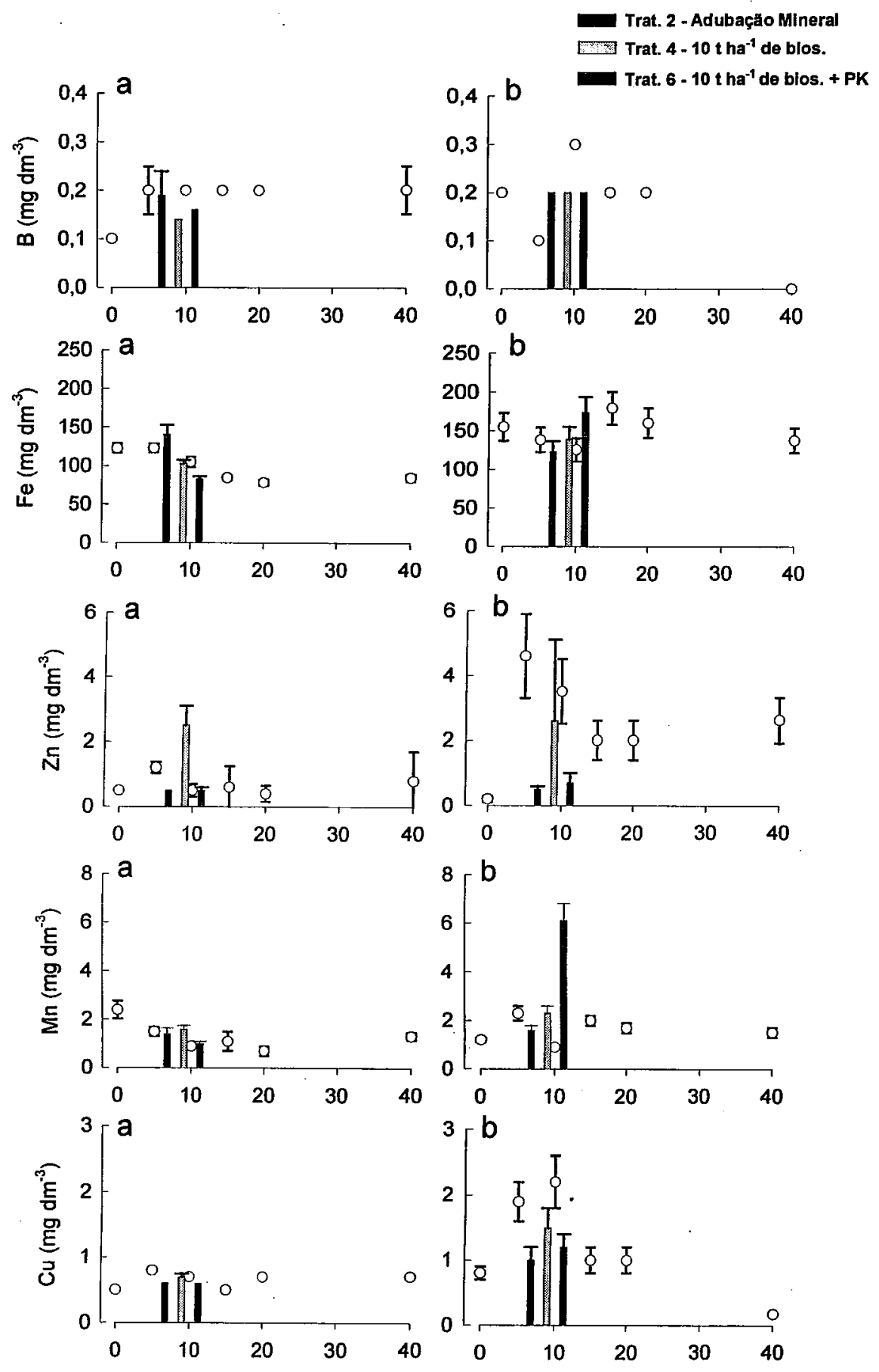

DOSE DE BIOSSÓLIDO (t ha-1)

Figura 4. Micronutrientes no solo (média \pm erro padrão), camada $0-5 \mathrm{~cm}$, nas entrelinhas do povoamento: a) aos seis meses e b) aos 13 meses pós-aplicação do biossólido. Os valores representados por símbolos circulares referem-se às doses crescentes de biossólido, 0 a $40 \mathrm{t} \mathrm{ha}^{-1}$, com suplementação de $\mathrm{K}$. 
- 12 meses

- 24 meses
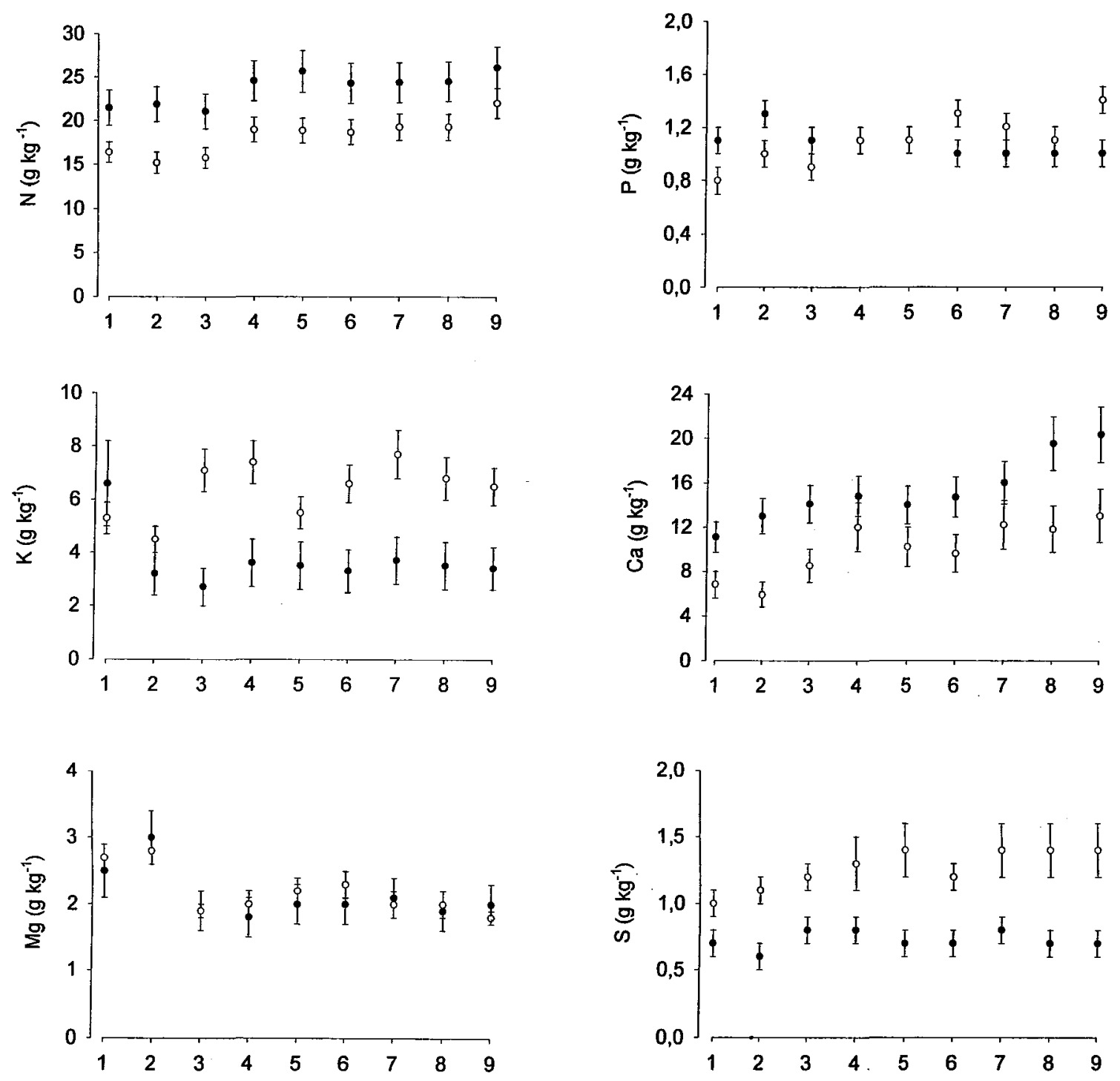

TRATAMENTO

Figura 5. Concentração foliar de macronutrientes (média \pm erro padrão) aos 12 e 24 meses de idade das plantas, oito e 20 meses pós-aplicação do biossólido, respectivamente, nos diferentes tratamentos. 

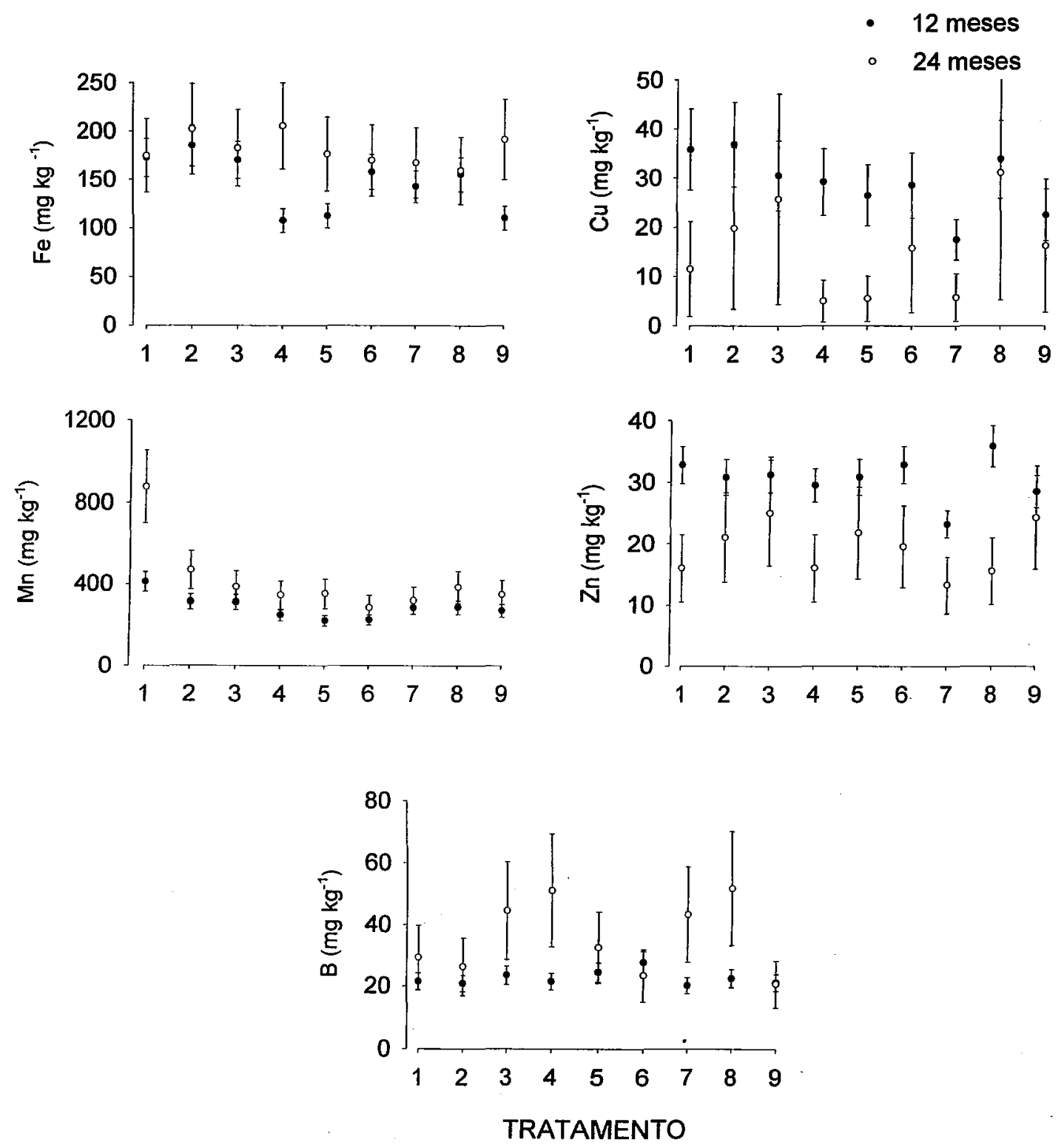

Figura 6. Concentração foliar de micronutrientes (média \pm erro padrão) aos 12 e 24 meses de idade das plantas, oito e 20 meses pós-aplicação do biossólido, respectivamente, nos diferentes tratamentos. 


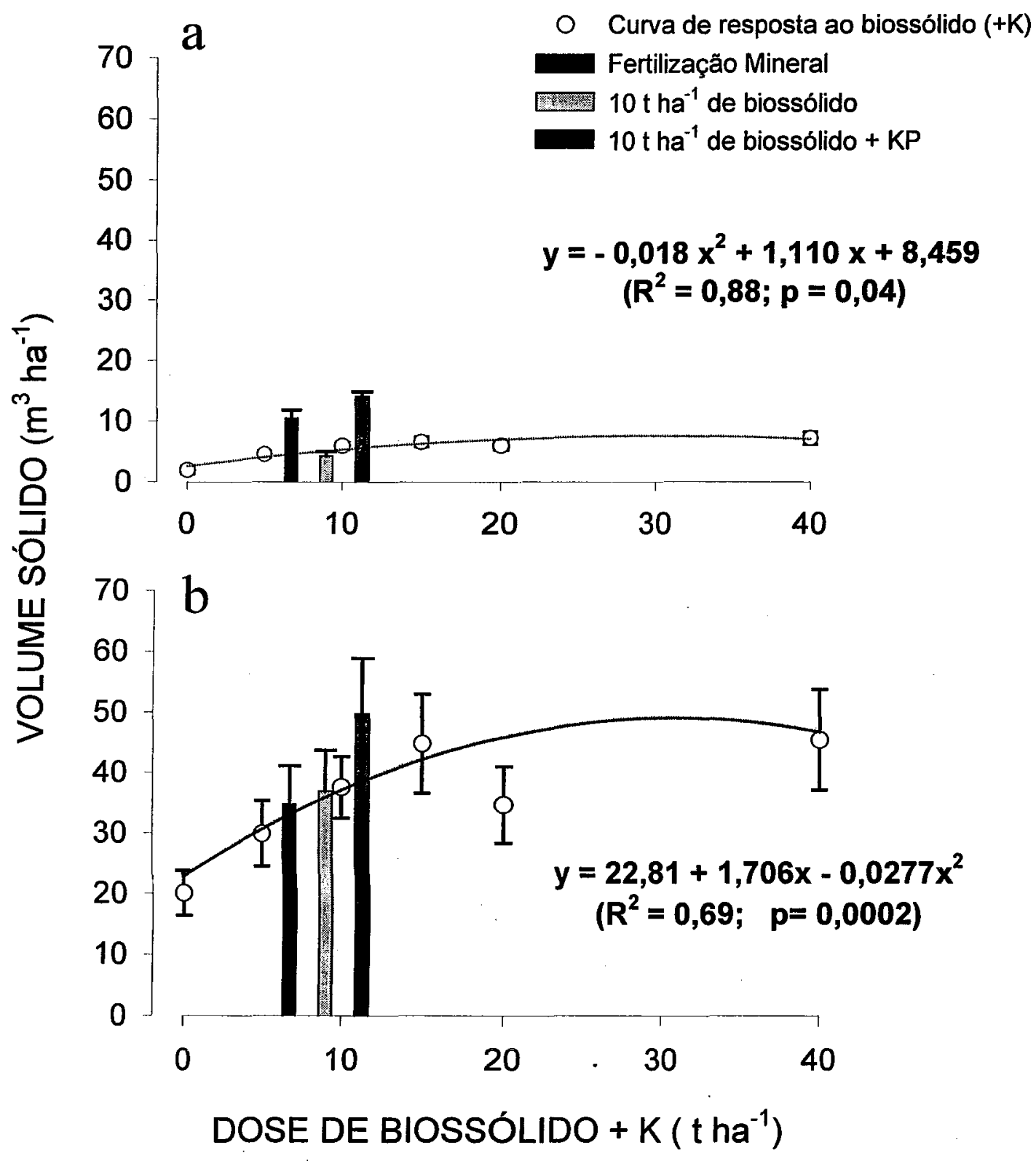

Figura 7. Curva de resposta à doses crescentes de biossólido, com suplementação de $\mathrm{K}$ (biossólido $+\mathrm{KCl}$ $=165 \mathrm{~kg} \mathrm{ha}^{-1}$ de $\left.\mathrm{K}\right)$, respostas à aplicações de $10 \mathrm{t} \mathrm{ha}^{-1}$ de biossólido sem suplementação de $\mathrm{K} \mathrm{e}$ com suplementação de $\mathrm{K}$ e $\mathrm{P}$ e, resposta à fertilização mineral sem biossólido dos povoamentos de Eucalyptus grandis com a) 17 meses e b) 24 meses de idade. Nesta idade tinham transcorrido 13 e 20 meses pós-aplicação do biossólido, respectivamente. 


\section{CONCLUSÕES}

1. Seis meses pós-aplicação do biossólido, para todos tratamentos, não foram constatadas alterações do $\mathrm{pH}$ e dos teores de $\mathrm{P}, \mathrm{Mg}, \mathrm{Zn}, \mathrm{Cu}$ e $\mathrm{B}$ nas camadas de solo analisadas. Foi observada elevação dos teores de $\mathrm{K}, \mathrm{Ca}$ e $\mathrm{S}$, e redução das concentrações de $\mathrm{Al}, \mathrm{Fe}$ e $\mathrm{Mn}$, dependendo da dose de biossólido aplicada.

2. Treze meses pós-aplicação do biossólido, foram constatadas elevação do $\mathrm{pH}$ e considerável elevação dos teores de $\mathrm{P}, \mathrm{Ca}, \mathrm{K}$ e S , somente, na camada $0-5 \mathrm{~cm}$. Os teores de $\mathrm{Ca}, \mathrm{Zn}$ e $\mathrm{Cu}$ foram maiores com doses de 5 a $10 \mathrm{tha}^{-1}$, decrescendo a partir da dose de $15 \mathrm{t} \mathrm{ha}^{-1}$. Os teores de $\mathrm{B}$ e $\mathrm{Mn}$, para a maioria dos tratamentos, não sofreram alterações. Abaixo desta camada, só os teores de $\mathrm{S}$ elevaram-se, aos seis e treze meses pós-aplicação do biossólido.

3. Para as duas épocas de amostragem do solo, com a elevação das doses de biossólido, ocorreu redução dos teores de $\mathrm{MO}$, somente na camada $0-5 \mathrm{~cm}$ de solo. As maiores reduções foram observadas aos seis meses pós-aplicação para as maiores doses: $20 \mathrm{e} 40 \mathrm{t}$ $\mathrm{ha}^{-1}$. Em compasso com a mineralização da $\mathrm{MO}$ no solo, os teores de $\mathrm{N}$ e $\mathrm{S}$ no tecido foliar elevaram-se com o aumento das doses de biossólido em ambas as épocas de amostragem.

4. A disponibilidade de $\mathrm{P}$ assimilável elevou-se, consideravelmente, com o tempo de contato do biossólido com o solo, em todos tratamentos que receberam biossólido. Refletindo este efeito, as árvores absorveram mais $\mathrm{P}$ e apresentaram maior crescimento. 
5. A aplicação de fertilizante fosfatado no sulco ou cova de plantio, conjuntamente com o biossólido, mostrou-se necessária para elevar o crescimento inicial das plantas, assegurando atendimento das elevadas demandas iniciais deste nutriente.

6. A aplicação de $10 \mathrm{tha}^{-1}$ de biossólido, sem suplementação de $\mathrm{K}$, elevou o teor deste nutriente, na camada de $0-5 \mathrm{~cm}$ de solo, a níveis considerados adequados para o crescimento de eucalipto. Por causa disto, a suplementação de $\mathrm{K}$ em plantações jovens de eucalipto poderá não ser necessária para doses de biossólido maiores que $10 \mathrm{tha}^{-1}$, quando as concentrações de $\mathrm{K}$ trocável forem médias $\left(0,08 \mathrm{a} 0,10 \mathrm{mmol}_{\mathrm{c}} \mathrm{dm}^{-3}\right)$.

7. As concentrações foliares de $\mathrm{K}$ foram semelhantes para todos tratamentos que receberam aplicações de biossólido, com ou sem suplementação de $\mathrm{K}$.

8. Houve nítida elevação da concentração de Ca no solo nos tratamentos que receberam biossólido, maior que no tratamento que só recebeu fertilização mineral, treze meses pós-aplicação. As alterações foram pequenas seis meses pós-aplicação.

9. A elevação das doses de biossólido, de $0 \mathrm{a} 40 \mathrm{t} \mathrm{ha}^{-1}$, resultou numa resposta quadrática em termos de produção de madeira. Aos 24 meses de idade, a aplicação de $10 \mathrm{t} \mathrm{ha}^{-1}$ de biossólido, com ou sem suplementação de $\mathrm{K}$, resultou num crescimento semelhante ao obtido com apenas aplicação de fertilização mineral.

10. A resposta à aplicação de biossólido elevou-se com a idade, refletindo, principalmente, os efeitos benéficos devidos à elevação da disponibilidade de nutrientes para as árvores. 


\section{REFERÊNCIAS BIBLIOGRÁFICAS}

ANDREOLI, C.V.; BONNET, B.R.P.; LARA, A.I.; WOLTER, F.R. Proposição de plano de monitoramento da reciclagem agrícola do lodo de esgoto no estado do Paraná (compact disc). In: CONGRESSO DE ENGENHARIA SANITÁRIA E AMBIENTAL, 19., Foz do Iguaçu, 1997. Trabalhos técnicos. Foz do Iguaçu: ABES, 1997a. p. 232-243.

ANDREOLI, C.V.; DOMASZAK, S.C.; FERNANDES, F.; LARA, A.I. Proposta preliminar de regulamentação para a reciclagem do lodo de esgoto no Paraná (compact disc). In: CONGRESSO DE ENGENHARIA SANITÁRIA E AMBIENTAL, 19., Foz do Iguaçu, 1997b. Trabalhos técnicos. Foz do Iguaçu: ABES, 1997b. p. 232-243.

ASSOCIAÇÃO NACIONAL DOS FABRICANTES DE PAPEL E CELULOSE. Relatório estatístico. São Paulo, 1995.

ASSOCIAÇÃO BRASILEIRA DE NORMAS TÉCNICAS. Fórum nacional de normatização: NBR 10.004 Resíduos Sólidos. Rio de Janeiro, 1987. 63 p.

AYUSO M.; PASCUAL, J.A. ; GARCIA, C.; HERNÁNDEZ, T. Evaluation of urban wastes for agricultural use. Soil Science and Plant Nutrition, v.42, n.1, p. 105-11, 1996. 
BARROS, N.F.; NOVAIS, R.F. Relação Solo-Eucalipto. Viçosa: Folha de Viçosa, 1990. $330 \mathrm{p}$.

BERTON, R.S.; CAMARGO, O.A.; VALADARES, J.M.A.S. Absorção de nutrientes pelo milho em resposta à adição de lodo de esgoto a cinco solos paulistas. Revista Brasileira de Ciência de Solo, v. 13, p. 187-192, 1989.

BEVACQUA, R.F.; MELLANO, V.J. Cumulative effects of sludge compost on crop yields and soil properties. Communications in Soil Science and Plant Analysis, v. 25, n. 3\&4, p. 395-406, 1994.

BOWLER. I. R. Recycling urban waste on farmland: on actor-network interpretation. Applied Geography, v. 19, p. 29-43, 1999

COMPANHIA DE TECNOLOGIA DE SANEAMENTO AMBIENTAL. Aplicação de biossólidos de sistemas de tratamento biológico em áreas agrícolas - Critérios para projeto e operação (Manual técnico). São Paulo: CETESB, 1999. 35 p.

DEFELIPO, B.V.; NOGUEIRA, A.V.; LOURES, E.G.; ALVAREZ, V.H. Eficiência agronômica do lodo de esgoto proveniente de uma indústria siderúrgica. Revista Brasileira de Ciência do Solo, v. 15, p. 389-393, 1991.

DESCHAMPS, C.; FAVARETTO, N. Efeito do lodo de esgoto na produtividade e desenvolvimento das culturas. In: ANDREOLI, C. V.; LARA, A. I.; FERNANDES, F. (Ed.). Reciclagem de Biossólido: Transformando problemas em soluções. Curitiba: SANEPAR, 1999. cap. 4, p. 181-237. 
DEUS, A. B. de; CASTRO, C. M. B. de. ; LUCA.,S. J. A disposição de Lodos de esgoto no solo. In: SIMPÓSIO INTERNACIONAL DE QUALIDADE AMBIENTAL, Rio Grande do Sul, 1996. Anais. p. 191-195. Rio Grande do Sul, 1996. p. 191195.

DUTCH, J.; WOLSTENHOLME, R. The effects of sewage sludge to a heathland site prior to planting with Sitka spruce. Forest Ecology and Management, v. 66, n. 1/3, p. 151-163, 1994.

FISKELL, J.G.A.; NEARY, D.G.P.; COMEFORD, N.B. Slash pine and understory interception of micronutrients mineralize from sewage sludge applied to a sandy, acidic forest soil. Forest Ecology and Management, v. 37, p. 27-36, 1990

FOLLE, F.; SHUFORD, J. W.; TAYLOR, R. W.; MEHADI, A. A.; TADESSE, W. Effect of sludge treatment, heavy metal, phosphate rate, and $\mathrm{pH}$ on soil phosporus. Communication of Soil Science and Plant Analysis, v. 26, n. 9 \& 10, p. 13691381, 1995.

GONÇALVES, J.L.M.; VAZ, L.M.S.; AMARAL, T.M. do; POGGIANI, F. Aplicabilidade de biossólido em plantações florestais: II Efeito na fertilidade do solo, nutrição e crescimento das árvores. In: BETTIOL, W.; CAMRGO, O.A., (Ed). Impacto Ambiental do Uso do Lodo de Esgoto. São Paulo: EMBRAPA Meio Ambiente, 2000a. 179-196 p.

GONÇALVES, J.L.M., STAPE, J.L.; BENEDETTI, V.; FESSEL, V.A.G.; GAVA, J.L. Reflexos do cultivo mínimo e intensivo do solo em sua fertilidade e na nutrição das árvores. In: GONÇALVES, J.L.M.; BENEDETTI, V., (Ed.). Nutrição e Fertilização Florestal. Piracicaba: IPEF, 2000b. p. 3-57. 
GONÇALVES, J.L.M.; BARROS, N.F.; NAMBIAR, E.K.S.; NOVAIS, R.F. Soil and stand management for short-rotation plantations. In: Nambiar, S. \& Brown, A., (Ed.). Management of soil, nutrients and water in tropical plantation forests. Camberra: ACIAR Austrália/CSIRO Austrália/CIFOR Indonésia, 1997. p. 379-418.

GONÇALVES, J.L.M.; RAIJ, B.; GONÇALVES, J.C. Florestais. In: RAIJ, B. van; CANTARELla, H.; QUAGGIO, J.A.; FURLANI, A.M.C., (Ed.). Recomendações de adubação e calagem para o Estado de São Paulo. Campinas: Instituto Agronômico de Campinas \& Fundação IAC, 1996. p. 245-259.

GONÇALVES, J.L.M.; BARROS, N.F.; NEVES, J.C.L.; NOVAIS, R.F. Níveis críticos de fósforo no solo na parte aérea de eucaliptos na presença e ausência de calagem. Revista Árvore, v. 10, n. 1, p. 91-104, 1986.

HANSEN, P.E.; JORGENSEN, S.E. Introduction to Environmental Management. Amsterdam: Elesvier, 1991. 403 p.

HARRISON, R.B.; REIS, M.D.G.F.; REIS, G.F.; GONÇALVES, J.L.M.; HENRY, C.H. COLE, D.W.; KING, R.; LEONARD, P.; COMPTON, J.; XUEI D. Closing the loop: the role of harvesting and transportation in maintaning productivity and returning organic waste to the forest. In: IX SEMINÁRIO DE ATUALIZAÇÃO SOBRE SISTEMAS DE COLHEITA DE MADEIRA E TRANSPORTE FLORESTAL, 9. Anais. Curitiba: UFPR, 1996. p. 101-108.

HENRY, C.L.; COLE, D.W.; HARRISON, R.B. Use of municipal sludge to restore and improve site productivity in forestry: the Pack Forest Sludge Research Program. Forest Ecology and Management, v. 60, n. 1/3, p. 137-149, 1994. 
LINDSAY, W. L.; NORVELL, W. A. Development of a DTPA soil test for zinc, iron, manganese and copper. Soil Science Society American Journal, v.42, p.421-428, 1978.

ILLERA,V.; WALTER, I.; SOUZA, P.; CALA, V. Short- term effects of biosolid and municipal solid waste applications on heavy-metal distribution in a degraded soil under a senmi-arid environment. The Science of the Total Environment, v. 255, p. $29-44,2000$.

LUCA, S.J. de.; IDE, C.N. ; MONTEGGIA, L. O. Lodos de ETEs Estabilizados por Cal e Ferrato (VI) de Potássio e a Recuperação de Áreas Degradadas. In: SIMPÓSIO INTERNACIONAL DE QUALIDADE AMBIENTAL, Rio Grande do Sul, 1996. Anais. p. 191-195. Rio Grande do Sul, 1996. p. 229-233.

MALAVOLTA, E.; VITTI, E.C.; OLIVEIRA, S.A. Avaliação do estado nutricional das plantas (princípios e aplicações). 2. ed. Piracicaba, Associação Brasileira para Pesquisa da Potassa e do Fosfato, 1997. 319 p.

MARTINS, L.G.C.; VALLE, C.F. do.; BARROS, N.F. de. Efeitos da aplicação do lodo da indústria de papel e celulose sobre características do solo e sobre a biomassa de raízes de Eucalipto. In: IUFRO CONFERENCE OF SILVICULTURE AND IMPROVEMENT OF Eucalyptus. Salvador, 1997. Anais. Colombo: EMBRAPA, 1997. p. 169-173.

McDONALD, M.A.; HAWKINS, B.J.; PRESCOTT, C.E; KIMMINS, J. P. Growth and foliar nutrition of western red cedar fertilized with sewage sludge, pulp sludge, fish silage, and wood ash on northern Vancouver Island. Canadian Journal of Forest Research, v. 24, p. 297-301, 1994. 
McNAB, W.H.; BERRY, C.R. Distribution of aboveground biomass in three pine species planted on a devasted site amended with sewage sludge or inorganic fertlizer. Forest Science, v. 31, n. 2, p. 373-382, 1985.

MELLO, F.A.F.; SOBRINHO, M.O.C.B.; ARZOLLA, S.; SILVEIRA, R.I.; NETTO, A.C.; KIEHL J.C. Fertilidade do Solo. São Paulo: Nobel, 1989. 400 p.

MELO, W.J. \& MARQUES, M.O. Potencial do lodo de esgoto como fonte de nutrientes para as plantas. In: BETTIOL, W. \& CAMARGO, O.A., ed. Impacto Ambiental do Uso do Lodo de Esgoto. São Paulo, EMBRAPA Meio Ambiente, 2000. p. 109-141.

MELO, W.J.; MARQUES, M.O.; SANTIAGO, G.; CHELLI, R.A.; LEITE, S.A.A. Efeito de doses crescentes de lodo de esgoto sobre frações da matéria orgânica e CTC de um latossolo cultivado com cana-de-açúcar. Revista Brasileira de Ciệncia do Solo, v. 18, p. 449-455, 1994.

MIYAZAWA, M.; GIMENEZ, S.M.N.; FERNANDEZ, F.; OLIVEIRA, E.L.D. de; SILVA, S.M.C.P.; Efeito do lodo de esgoto nos teores de metais pesados no solo e na planta. In: Andreoli, C.V.; LARA, A.I.; FERNANDES, F. (Org.). Reciclagem de Biossólido: Transformando problemas em soluções. Curitiba: SANEPAR, 1999. p. 204-225.

NOVAIS, R.F.; BARROS, N.F.; NEVES, J.C.L.; COUTO, C. Níveis críticos de fósforo para o eucalipto. Revista Árvore, v.6, p. 29-37, 1982.

OLIVEIRA, F.C.; MARQUES, M.O.; BELLINGIERI, P.A.; PERECIN, D. Lodo de esgoto como fonte de macronutrientes para a cultura do sorgo granífero. Scientia Agricola, Piracicaba, v. 52, n. 2, p. 360-367, 1995. 
PAGE, A. L.; MILLER, P. H.; KEENEY, D. F. Methods of soil analysis. 2. ed. Madison: ASA, SSSA, 1982. 1159 p.

PHILLIPS, R. FISHER, J.T., MEXAL, J.G. Fuelwood Production Utilizing Pinus eldarica and Sewage Sludge Fertilizer. Forest Ecology and Management, v. 16, p. 95-102, 1986.

POLGLASE, P. J.; MYERS, B. J. Tree plantations for recycling effluent an biosolids in Australia. In: ELDRIGE, K. G.; CROWE, M. P.; OLD, K. M. (Ed.). THE JOINT AUSTRALIAN/JAPANESE WORKSHOP HELD IN AUSTRALIA, 1., Sidney, 1996. Proceedings. Calligwood: CSIRO, 1996. p. 100-109.

RAIJ, B. van; CANTARELlA, H.; QUAGGIO, J.A.; FURLANI, A.M.C., (Ed.). Recomendações de adubação e calagem para o Estado de São Paulo. 2. ed. Campinas: Instituto Agronômico de Campinas \& Fundação IAC, 1996. 285p.

RAIJ, B. van; QUAGGIO, J.A.; CANTARELLA, H.; FERREIRA, M.E.; LOPES, A.S.; BATAGLIA, O.C. Análise química do solo para fins de fertilidade. Campinas: Fundação Cargill, 1987. 170 p.

RIDDEL-BLACK, D.M.; ROWLAND, C. \& SNELSON, A. Short rotation forest productivity using sewage sludge as a nutrient source. In: CHARTIER, P.; FERRERO, G.L.; HENIGS, U. M. S.; HULTBERG, S.; SACHAU, M. \& WINBLED, M. Biomass for Energy and the Enviroment. Proceedings of the 9th European Bioenregy Conference. Vol 1. Pergamon. Dinamarca. 1996.

RIEKERK, H. Effects of sludge disposal drainage solution of two forest. Soil Forest Science, v. 27, n. 4, p. 792-800, 1981. 
SANTOS, H.F. dos; GUIMARÃES, M.O.; GIUSTI, P.E.A. Uso do lodo de Ete's em reflorestamentos. In: Encontro Técnico da Associação de Engenheiros da SABESP (AESABESP), 7., São Paulo, 1997. Anais. São Paulo: SANEAS, 1997. 1-27 p.

SARRUGE, J.R.; HAAG, H.P. Análise química em plantas. Piracicaba, ESALQ, 1974. $56 \mathrm{p}$.

SILVA, F.C. da. Uso agronômico de lodo de esgoto: efeitos em fertiliadade do solo e qualidade de cana-de-açúcar. Piracicaba, 1995. 165p. Dissertação (M.S.)- Escola Superior de Agricultura “Luiz de Queiroz”, Universidade de São Paulo.

SIMS, R.E.H. Utilisation of waste organic matter. Journal Agriculture, Ecosystems \& Environment, v.58, p. 91-95, 1996.

SHIMP, G.F.; VASCONCELOS, H.O.B.; VILELA, P.; PERCINOTTI, C.; STEFANI, M.C.G.; CARVALHO, F.V. Progress report on São Paulo's plans for biosolids management. In: ANUAL CONFERENCE \& EXPOSITION OF THE WATER ENVIRONMENT FEDERATION, 6, Dallas, 1996. Proceedings. p. 491-497. ??

SKOUSEN J.; KLINGER, C. Sewage sludge land application progam in West Virginia. Journal of Soil and Water Conservation, v.48, n. 2, p. 145-151, 1998.

SORT, X:; ALCAÑIZ, J.M. Modification of soil porosity after application of sewage sludge. Soil \& Tillage Research, v.49, p. 337-345, 1999.

SPOSITO, G. The Chemistry of Soil. New York: Oxford University, 1989. 277 p.

STEVENSON, F.J. Cycles of Soil. Canada : Jhon Wiley \& Sons, 1986. 380 p. 
SUI, Y.; THOMPSON, M.L: Phospurus sorption, desorption, and buffering capacity in a biosolids-amended mollisol. Soil Science Society American Journal, v. 64, p. 164-169, 2000.

TEDESCO, M.J.; SELBACH, P.A; GIANELLO, C.; CAMARGO, F.A.O. Resíduos orgânicos no solo e os impactos no ambiente. In: SANTOS, G.A.; CAMARGO, F.A.O. (Ed.). Fundamentos da matéria orgânica no solo: Ecossistemas Tropicais e Subtropicais. Porto Alegre: GENESIS, 1999. 159-196 p.

TISDALE, S.L.; NELSON, W.L.; BEATON, J.D. Soil fertility and fertilizers. USA: Macmillan, 1985. $754 \mathrm{p}$.

TSAI, S.M.; ROSSETO, R. Transformações microbianas do fósforo. In: CARDOSO, E.J.B.N.; TSAI, S.M. \& NEVES, M.C.P., (Org.). Microbiologia do Solo. Campinas: Sociedade Brasileira de Ciência do Solo, 1992. 231-242 p.

TSUTYA, M.T. Alternativas de disposição final de biossólidos gerados em estações de tratamento de esgotos. In: BETTIOL, W.; CAMRGO, O.A., (Ed). Impacto Ambiental do Uso do Lodo de Esgoto. São Paulo: EMBRAPA Meio Ambiente, 2000. p. 69-105.

U.S. ENVIRONMENTAL PROTECTION AGENCY 1995. EPA/832-B93-005. A Guide to the Biosolids: Risk Assessments for the EPA Part 503. Fed. Reg. $144 \mathrm{p}$.

U.S. ENVIRONMENTAL PROTECTION AGENCY 1993. 40 CFR Parts 257, 403 and 503. Final rules: Standards for tthe use of sewage sludge. Fed. Reg. v. 58, n. 32, p. 9248-9415. 
VEIGA, R. A. A. Dendrometria e Inventário Florestal. FEPAF. Boletim Didático n. 1.1984. $108 \mathrm{p}$.

WANG, Min-Jian. Land application of sewage sludge in China. The Science of the Total Environment, p. 149-160, 1997.

WEBBER, M. D.; SHAMES, A. Land utilization of sewage: a discussion paper. Expert Commitee on soil and water management. Toronto, $1984.48 \mathrm{p}$.

WEETMAN, G.F.; McDONALD, M.A.; PRESCOTT, C.E.; KIMMINS J.P. Responses of western hemlock, Pacific silver fir, and western red cedar plantations on northern Vancouver Island to applications of sewage sludge and inorganic fertilizer. Canadian Journal of Forest Research, v. 23, p. 1015-1020, 1993. 